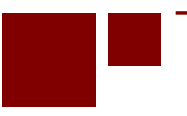

\title{
LABOR FORCE DYNAMICS IN THE GREAT RECESSION AND ITS AFTERMATH: IMPLICATIONS FOR OLDER WORKERS
}

\author{
Gary Burtless \\ CRR WP 2016-1 \\ July 2016
Center for Retirement Research at Boston College
Hovey House
140 Commonwealth Ave
Chestnut Hill, MA 02467 \\ Tel: 617-552-1762 Fax: 617-552-0191 \\ http://crr.bc.edu
}

Gary Burtless is the John C. and Nancy D. Whitehead Chair in Economic Studies at the Brookings Institution. The research reported herein was performed pursuant to a grant from the U.S. Social Security Administration (SSA) funded as part of the Retirement Research Consortium. The opinions and conclusions expressed are solely those of the author and do not represent the opinions or policy of SSA, any agency of the federal government, the Brookings Instituition, or Boston College. Neither the United States Government nor any agency thereof, nor any of their employees, makes any warranty, express or implied, or assumes any legal liability or responsibility for the accuracy, completeness, or usefulness of the contents of this report. Reference herein to any specific commercial product, process or service by trade name, trademark, manufacturer, or otherwise does not necessarily constitute or imply endorsement, recommendation or favoring by the United States Government or any agency thereof. The author gratefully acknowledges the excellent research assistance of Mattan Alalouf of the University of Michigan and Eric Koepcke of The Brookings Institution.

(C) 2016, Gary Burtless. All rights reserved. Short sections of text, not to exceed two paragraphs, may be quoted without explicit permission provided that full credit, including (C notice, is given to the source. 


\begin{abstract}
About the Center for Retirement Research
The Center for Retirement Research at Boston College, part of a consortium that includes parallel centers at the University of Michigan and the National Bureau of Economic Research, was established in 1998 through a grant from the Social Security Administration. The Center's mission is to produce first-class research and forge a strong link between the academic community and decision-makers in the public and private sectors around an issue of critical importance to the nation's future. To achieve this mission, the Center sponsors a wide variety of research projects, transmits new findings to a broad audience, trains new scholars, and broadens access to valuable data sources.
\end{abstract}

Center for Retirement Research at Boston College

Hovey House

140 Commonwealth Ave

Chestnut Hill, MA 02467

Tel: 617-552-1762 Fax: 617-552-0191

http://crr.bc.edu

Affiliated Institutions:

The Brookings Institution

Massachusetts Institute of Technology

Syracuse University

Urban Institute 


\begin{abstract}
Unlike prime-age Americans, who have experienced declines in employment and labor force participation since the onset of the Great Recession, Americans past 60 have seen their employment and labor force participation rates increase. In order to understand the contrasting labor force developments among the old, on the one hand, and the prime-aged, on the other, this paper develops and analyzes a new data file containing information on monthly labor force changes of adults interviewed in the Current Population Survey (CPS). The paper documents notable differences among age groups with respect to the changes in labor force transition rates that have occurred over the past two decades. What is crucial for understanding the surprising strength of old-age labor force participation and employment are changes in labor force transition probabilities within and across age groups.
\end{abstract}

The paper identifies several shifts that help account for the increase in old-age employment and labor force participation:

- Like workers in all age groups, workers in older groups saw a surge in monthly transitions from employment to unemployment in the Great Recession.

- Unlike workers in prime-age and younger groups, however, older workers also saw a sizeable decline in exits to nonparticipation during and after the recession. While the surge in exits from employment to unemployment tended to reduce the employment rates of all age groups, the drop in employment exits to nonparticipation among the aged tended to hold up labor force participation rates and employment rates among the elderly compared with the nonelderly. Among the elderly, but not the nonelderly, the exit rate from employment into nonparticipation fell more than the exit rate from employment into unemployment increased.

- The Great Recession and slow recovery from that recession made it harder for the unemployed to transition into employment. Exit rates from unemployment into employment fell sharply in all age groups, old and young.

- In contrast to unemployed workers in younger age groups, the unemployed in the oldest age groups also saw a drop in their exits to nonparticipation. Compared with the nonaged, this tended to help maintain the labor force participation rates of the old. 
- Flows from out-of-the-labor-force status into employment have declined for most age groups, but they have declined the least or have actually increased modestly among older nonparticipants.

Some of the favorable trends seen in older age groups are likely to be explained, in part, by the substantial improvement in older Americans’ educational attainment. Better educated older people tend to have lower monthly flows from employment into unemployment and nonparticipation, and they have higher monthly flows from nonparticipant status into employment compared with less educated workers.

The policy implications of the paper are:

- A serious recession inflicts severe and immediate harm on workers and potential workers in all age groups, in the form of layoffs and depressed prospects for finding work.

- Unlike younger age groups, however, workers in older groups have high rates of voluntary exit from employment and the workforce, even when labor markets are strong. Consequently, reduced rates of voluntary exit from employment and the labor force can have an outsize impact on their employment and participation rates.

- The aged, as a whole, can therefore experience rising employment and participation rates even as a minority of aged workers suffer severe harm as a result of permanent job loss at an unexpectedly early age and exceptional difficulty finding a new job.

- Between 2001 and 2015, the old-age employment and participation rates rose, apparently signaling that older workers did not suffer severe harm in the Great Recession.

- Analysis of the gross flow data suggests, however, that the apparent improvements were the combined result of continued declines in age-specific voluntary exit rates, mostly from the ranks of the employed, and worsening reemployment rates among the unemployed. The older workers who suffered involuntary layoffs were more numerous than before the Great Recession, and they found it much harder to get reemployed than laid off workers in years before 2008. The turnover data show that 
it has proved much harder for these workers to recover from the loss of their latecareer job loss. 


\section{Introduction}

Older American workers, like younger ones, experienced a spike in layoffs during the Great Recession. As was the case for prime-age and younger adults, older workers saw a sizeable increase in long-term unemployment. The job market recovery was agonizingly slow for workers in all age groups. In contrast to younger adults, however, older Americans have seen increases in their labor force participation and employment since the onset of the Great Recession (see Figure 1). Seven years after the beginning of that recession, every age group younger than age 60 saw a drop in both labor force participation and employment-to-population ratios, contributing to an overall decline in adult participation and employment rates. The participation rate of adults 16 and older was lower in 2015 than at any time since 1977. While roughly half the decline is traceable to the aging of the population, which has boosted the fraction of adults past retirement age, the other half is due to falling participation in age groups that once had higher rates of engagement in the job market (U.S. Council of Economic Advisers 2014). In contrast to the experience of younger Americans, however, those in their 60s and 70s have managed to increase their participation and employment.

The favorable experience of older people cannot be explained by benign labor market trends that sheltered aged workers compared to their nonelderly counterparts. The peak unemployment rate of Americans past 60 increased proportionately just as much as it did among prime-age and younger groups. Layoff rates surged, and laid-off older workers experienced the same hardships finding new jobs as younger workers. The surprising strength of old-age employment and participation rates in the face of a severe downturn raises questions about the labor market dynamics that allowed old-age employment rates to rise while employment in younger age groups fell. Statistics on joblessness, especially long-term joblessness, suggest that older workers were severely harmed by the recession. Despite this harm, old-age employment rates have edged up since 2007.

The increased employment rate of older adults must be understood in relation to employment trends seen in the decade and a half before the Great Recession, when old-age employment was rising even faster than has been the case since 2007. The slower increase in employment after 2007 has been the result of one or more changes in underlying transition rates into or out of employment. The exit rate from employment as a result of layoffs certainly increased at least temporarily during the recession, but exits as a result of voluntary quits fell, as 
we shall see. The rate of exit from unemployment into employment declined, and the probability of moving directly from out-of-the-labor-force status into employment fell, at least temporarily. Conceivably, older workers experienced lower layoff rates in the current recovery than they did in previous economic expansions. If laid off older workers were more persistent in their search for jobs, they may have ultimately been more successful in their efforts to prolong their careers compared with laid off workers in earlier recessions and relative to prime-age workers. These possibilities can be investigated using labor force transition probabilities observed in the monthly Current Population Survey (CPS) files.

In this paper I develop and analyze a data file containing information on labor force transitions of adults included in the CPS. I create records that identify the age and other individual characteristics of CPS respondents, calculating monthly labor force status changes for those respondents whose monthly interviews can be matched in successive monthly interviews. The file permits me to analyze labor force transitions by age and other characteristics. Unfortunately, the records have not been processed using U.S. Bureau of Labor Statistics (BLS) procedures that make the estimated labor market flows consistent with the monthly crosssectional estimates of Americans' labor force status. As a result, the estimates of transition probabilities cannot be used to generate accurate monthly predictions of participation, employment, or unemployment rates within an age group.

What matters for understanding recent labor force trends, however, are changes in average flow rates over time. Under the assumption that biases in accurately determining flow rates are roughly constant over time, we can use unadjusted estimates of the flows to compare transition rates across age groups, and within a given age group, over time. The analysis uncovers sizeable differences between the labor force transition patterns of young and old workers. More importantly, it documents notable differences between age groups with respect to the changes in labor force transition rates over the past two decades. In particular, workers and labor force participants in the oldest age groups have seen reductions in their rates of exit from employment and unemployment into nonparticipation. Even though all age groups have experienced increases in their exit rates from employment into unemployment and reductions in their transition rates from unemployment into employment, changes in other labor market flows have helped offset the impact of these developments on aged. 
The remainder of the paper is organized as follows. The next section offers a brief introduction to the BLS gross flow data and, in particular, to the uses and limitations of the data. The second section describes the procedures used to create the data file analyzed in this study. It presents straightforward tabulations of the data that permit us to compare labor force transition patterns across age groups and over useful comparison periods. The third main section extends the analysis to consider the impact of older Americans' rising educational attainment on the main results. The paper concludes with a brief survey of central findings.

\section{Labor Force Transitions}

The best-known gauge of labor market hardship is the unemployment rate. This statistic measures the percent of adults looking for a job or currently employed who do not currently hold a job. The BLS, which calculates and publishes the unemployment rate, does so based on a monthly household CPS survey administered by the U.S. Census Bureau. Census interviewers contact about 60,000 households, and these respondents are asked about the labor force status of all adults in their household. In total, the interviews gather information on the labor force status of approximately 110,000 people every month. Based on the reported experiences of these people, the BLS calculates the percentage of adults who are currently employed, currently actively seeking work but jobless (unemployed), and currently out of the labor force (neither employed nor actively seeking work).

If the CPS were a strictly cross-sectional survey, all the information needed to calculate the monthly unemployment rate would be available from each month's point-in-time survey. For a variety of reasons, however, the CPS is a longitudinal, as well as a cross-sectional, survey. Every month about three-quarters of households interviewed in the previous month are retained for reinterview in the current month. After a household is contacted for an initial interview it is then reinterviewed for the next three months, not contacted for the following eight months, then reinterviewed for the following four successive months. In all, households are potentially interviewed eight times. For six of the monthly interviews respondents' answers in the current month can be compared with those covering the same person in the immediately preceding month. That is, analysts can not only determine the person's current labor force status but also any change in status that has occurred compared with the previous month. It is these 
comparisons, for up to three-quarters of the CPS sample, that permit us to determine the gross labor market flows from one labor force status to another. ${ }^{1}$

Suppose we designate the labor force status “employed” as $E$, “unemployed” as $U$, and "not in the labor force" as $N$. Then we can designate the nine possible labor force transitions from last month's status to the current month’s as follows:

\begin{tabular}{|c|c|c|c|}
\hline \multicolumn{4}{|c|}{ Labor Market Flows from Previous to Current Month } \\
\hline \multicolumn{4}{|c|}{ Labor force status in current month: } \\
\hline Status in previous month: & Employed & Unemployed & Not in labor force \\
\hline Employed & $E=>E$ & $\mathrm{E}=>\mathrm{U}$ & $\mathrm{E}=>\mathrm{N}$ \\
\hline Unemployed & $\mathrm{U}=>\mathrm{E}$ & $\boldsymbol{U}=>\boldsymbol{U}$ & $\mathrm{U}=>\mathrm{N}$ \\
\hline Not in labor force & $\mathrm{N}=>\mathrm{E}$ & $\mathrm{N}=>\mathrm{U}$ & $N=>N$ \\
\hline
\end{tabular}

The highlighted cells in the table indicate "transitions" in which people retain their labor force status in the preceding month. The other six cells indicate transitions where there has been a change in status, say, from employment to unemployment $(E=>U)$ or from not in the labor force to employment $(N=>E)$.

In principle it should be possible to derive accurate estimates of the percent of CPS respondents in the current month who hold each labor force status, $E, U$, and $N$, based on our estimates of the same percentages in the previous month plus our estimates of the nine labor force flows identified in the table above. For a number of reasons, however, this is not true in practice (Ilg 2005; Frazis, Robinson, Evans, and Duff 2005). Obviously, our estimates of labor force flows are based solely on the experiences of the three-quarters of the CPS sample that is reinterviewed, whereas our estimates of the number of persons in each labor force status are based on 100 percent of survey respondents, one-quarter of whom were not interviewed in the previous month. If the newly entering CPS respondents have somewhat different labor force statuses than the reinterviewed respondents, the labor force status changes of reinterviewed respondents will not generate accurate predictions of the labor force statuses of the full CPS sample. There is a tendency for respondents to give systematically different responses regarding labor force status in successive CPS interviews, and this generates systematic errors in estimates of labor force flows.

\footnotetext{
${ }^{1}$ A very clear description of the CPS interviewing procedure and computation of labor market status changes can be found in Ilg (2005).
} 
One reason for the systematic error is sample attrition. The Census Bureau does not record status responses based on a fixed sample of people. Rather, it attempts to obtain responses about the adults who live in a constant set of physical addresses. Households may move from one month to the next, household members may change from one month to the next, or respondents who agree to be interviewed in one month may refuse to do so in the next. If the labor market statuses (and status changes) of adults who are likely to leave the sample differ systematically from the statuses of adults who remain in the sample, our estimates of labor market flows derived from the CPS may produce biased indicators of the flows.

An important issue in the measurement of gross flows is so-called "classification error." Respondents or interviewers almost certainly misclassify the current labor force status of a fraction of people in each month's sample. Arguably, the classification errors are offsetting, leaving us with tolerably accurate estimates of the percentage of adults in each status. The effects of classification error on estimates of labor force flows are not so benign. A classification error in one month followed by a correct response in the following month can generate a spurious labor market flow from one status to another, yielding an overstatement of gross flows to a changed status. A more subtle problem is that the standard classification, laid out in the table above, does not take account of changes in the population within the scope of the CPS. The population that is used to estimate the unemployment rate consists of the noninstitutionalized adult population age 16 and older that resides in the United States. People turning 16 enter the sample every month as do people who move into the U.S. and those who leave institutions. People who die, become institutionalized, or leave the country of course move outside the scope of the CPS. This issue is particularly important for a study, like the current one, that focuses on the labor force transitions of adults in fixed age groups. I classify adults by their age in the first month of a possible transition, but some of these people will be in an older age group in the second month they are interviewed. At the same time, other people who are classified in a younger age group will "age” into the age group of interest by the time of the reinterview. The moves in and out of an age group can produce a discrepancy between the reported percent of age-group members who are in each labor force status and the percentages implied by the gross flows between labor force states.

BLS recognizes each of the problems just described. Indeed, for many years the problems were considered so severe that the bureau ceased publishing estimates of monthly 
gross flows. Without sophisticated adjustments, the gross flows indicated in matched CPS surveys produced estimates that were clearly incompatible with the cross-sectional estimates of respondents' labor force states. The BLS resumed publishing estimates based on a new method for calculating flow statistics so they are compatible with monthly estimates of the percentage of adults who are in each labor force status (Frazis et al. 2005). The estimates are useful for interpreting the changes in the stock of potential labor force participants who are employed, unemployed, or out of the labor force and, in particular, for understanding the cyclical rise and fall in the unemployment rate, labor force participation rate, and employment-to-population ratio.

In Figure 3, for example, I present estimates based on the BLS gross flow data of exit rates from the three labor force states. Exit rates are calculated as the percentage of people in a labor market status in a given month who exit to a different status in the following month. The top panel shows exit rates from employment to nonparticipation and to unemployment. The middle panel shows exit rates from unemployment to employment and to nonparticipation. The bottom panel shows exit rates from nonparticipation to employment and unemployment. The shaded areas in the charts indicate the dates of recessions as determined by the National Bureau of Economic Research (NBER) Business Cycle Dating Committee. Note that the Dating Committee defines a recession as "a significant decline in economic activity spread across the economy, lasting more than a few months.” Thus, properly understood a recession is the period of contraction in a business cycle. During the initial period of expansion or recovery after a recession ends, the economy may continue to be in a depressed state, but economic activity is no longer in decline. The economy is growing, even if very slowly.

Although the BLS publishes seasonally adjusted estimates of gross flow data, I have derived the exit rate estimates in Figure 3 using seasonally unadjusted data. As an approximation to seasonal adjustment, I present the 12-month centered moving average estimate of each exit rate. ${ }^{2}$ The results show clear cyclical patterns in several of the exit rate series. Not surprisingly, exits from employment to unemployment increase during recessions and decline in economic expansions. When the experiences of both sexes and all age groups are averaged together, as they are in Figure 3, exits from employment into nonparticipation greatly outnumber exits from employment into involuntary unemployment. That is because many job separations

\footnotetext{
${ }^{2}$ Since I do not have access to seasonally adjusted flow data for the age sub-groups analyzed below, this procedure makes the aggregate BLS series more comparable to the sub-group results presented below.
} 
represent voluntary quits so a worker can return to school, take up care of children or other family members, or enter retirement. As we shall see, this pattern is particularly noticeable in older age groups, where exits to nonparticipation may exceed exits to unemployment by a ratio of 5- or even 10-to-1. Exit rates from unemployment, both to employment and to nonparticipation, decline before and during recessions and then tend to increase during expansions. Exit rates from nonparticipation to employment decline in recessions, as job finding becomes harder, but then eventually recover during the later stages of an expansion. On the other hand, exit rates from nonparticipation to unemployment tend to increase in recessions, when job finding becomes more difficult, but then gradually decline as an expansion continues.

The data cover a 22-year span from 1994 through 2015. This period included two recessions, in 2001 and 2008-2009, and three economic expansions. It is easy to see in the charts which of the two recessions had the bigger impact on the labor market. The increase in the $E=>U$ exit rate was considerably greater in the 2008-2009 recession, the drop in the $U=>E$ exit rate was larger, and the decline in the $N=>E$ exit rate was both larger and more sustained. Partially offsetting the implied adverse impacts of these developments on the adult employment rate was a decline in the rate of exit from employment into nonparticipation during and after the later recession. Besides the cyclical patterns just mentioned, the chart also shows two notable secular trends in exit rates. Since the 1990s there has been a sizeable long-term decline in the rate of exit from unemployment into employment. In contrast, there has been a much smaller secular change in the rate of exit from unemployment to nonparticipation. Since the overall exit rate from unemployment is the sum of the exit rates to employment and nonparticipation, it follows that unemployment has become more persistent since the 1990s. This is consistent with independent information about the median and average duration of unemployment spells in progress, also ascertained in the CPS interviews (Kosanovich and Sherman 2015). Between 1995-2000 and 2013-2015, both the average and median duration of unemployment spells in progress approximately doubled. Because the exit rate from unemployment declined, a much higher percentage of unemployment spells in 2013-2015 lasted longer than six months, a threshold commonly used to identify lengthy unemployment spells.

The bottom panel of Figure 3 also shows a long-term (secular) decline in the monthly exit rate from nonparticipation into employment. This may reflect sustained weakness in the job market, which makes it hard for nonparticipants to find work. Alternatively, the decline in the 
$N=>E$ exit rate may reflect population aging. The oldest members of the baby boom generation turned 60 in 2006, an age at which voluntary retirements begin to rise rapidly. Each year after 2006 brought millions of additional Americans to ages at which permanent labor force withdrawal is common. A growing proportion of adults past 16 were attaining ages where it is uncommon for nonparticipants to re-enter the labor force, either as workers or active job seekers.

It is probable that all of the exit rates displayed in Figure 3 are affected by the age structure of the population. It is also clear that the aggregate gross flow data published by the BLS do not help us understand the distinctive labor force trends of younger and older Americans displayed in Figures 1 and 2. The remainder of this paper focuses on analysis of labor force flows within narrower age groups. The primary goal is to uncover differences in the response of older and younger age groups during the Great Recession of 2008-2009 and the sluggish recovery from that downturn.

\section{Measuring Flows in Narrower Age Groups}

The published BLS estimates of labor market flows cover the entire noninstitutionalized population past age 16, separately by gender. In order to analyze flow data for women and men in narrower age groups, it is necessary to develop estimates of flows based on matched monthly interview data from the public-use version of the CPS files. Longitudinal matching requires identification of the same individual in two successive monthly interviews. The problems of successfully matching records for the same individual over successive interviews are discussed by Madrian and Lefgren (1999), who also propose an algorithm for matching CPS records [http://www.nber.org/data/cps_match.html].

We matched records based on Census-assigned household and family IDs, gender, age, and race. The analysis is based on CPS interviews conducted from January 1994 through December 2014, yielding information on individual labor force transitions between January 1994 to February 1994, February 1994 to March 1994, and so on up through November 2014 to December 2014. Because of changes in BLS record identification procedures, we were unable to make reliable matches for certain months in 1995 and 2004, but we succeeded in making matches for a total of 246 monthly record pairs. Our analysis sample consists of CPS sample members who were between ages 27 and 76 in the first month of the matched survey records. In all, the analysis sample consists of 13.1 million matched interview records, of which two-thirds 
reflect labor market transitions beginning with an employment spell. About 3 percent of matched records begin with an unemployment spell, and 29 percent begin with a spell of nonparticipation (see Appendix Table 1). The sample sizes are of course much smaller when we focus on narrower age groups. Appendix Table 2 shows the number of matched interview records, by initial labor force status and gender, for 5-year age groups. In the oldest age groups individuals who have matched records beginning with an unemployment spell are not very numerous.

Monthly exit rates are calculated as a percent of the number of persons in a particular labor force status in the preceding month. For example, the $E=>U$ exit rate is calculated as a percent of the number of employed people with matched CPS records in the previous month. The computations weight each observation by its CPS longitudinal weight in the earlier month. (Because the number of matched records is roughly three-quarters the number of total interviews conducted in a given month, an observation's longitudinal weight will differ from its basic CPS weight.) When I report an average exit rate over a multi-month period, it is the simple arithmetic average of the exit rates of the months included in the period. Unlike the aggregate BLS flow statistics displayed in Figure 3, the estimates of flows have not been adjusted so that they are consistent with the monthly distributions of labor force statuses. The sophisticated methods used to reconcile the stock and flow data described by Frazis et al. (2005) could of course be applied to data for narrower age and gender groups, but those adjustments are beyond the scope of this project. The basic research method adopted here is to compare straightforward estimates of labor market flows across age groups and across time in order to shed light on the differential labor force trends of younger and older Americans since 2007.

\section{Exits from Employment to Unemployment}

The time series pattern of an exit rate can differ substantially across age groups. Figures 4 and 5, for example, show exit rates from employment to unemployment in six different age groups. The results in Figure 4 shows time series for women aged 37 to 41 and 47 to 71 . The women are divided into 5-year age groups. Each data point in the chart shows the 12-month centered average of exit rates at the indicated date. The breaks in the time series occur when it is not possible to calculate exit rates for 12 consecutive months, primarily because a change in Census household identification procedures makes it impossible to match CPS records in two 
successive months. A clear cyclical pattern in exit rates can be seen for the five younger age groups - 37 to 41,47 to 51,52 to 56,57 to 61 , and 62 to $66 .{ }^{3}$ There is an increase in the rate of exit into unemployment before, during, or after a recession, and the exit rate eventually declines in the following expansion. A broadly similar pattern can be seen in the oldest age group, but it is less pronounced than it is for most of the younger groups. We also see differences in exit rates that persist across the business cycle. For example, women who are 37 to 41 years old nearly always have a higher exit rate into unemployment compared with women who are 10 years older.

Figure 5 shows identical time series statistics for men in the same six age groups. These show many of the same patterns seen among women. The cyclical pattern of increasing exit rates into unemployment in recessions and declining rates in recoveries is the same for men as it is for women, though it is more pronounced in the case of men. The cyclical pattern is especially prominent in the 2008-2009 recession when exit rates into unemployment approximately doubled for all but the oldest age group. As was the case for women, younger age groups of men tend to have higher exit rates into unemployment compared with the older ones. This is particularly notable near the trough of the 2008-2009 recession, when exit rates into unemployment peaked. The peak centered-average exit rate among 37-to-41 year-old men was about 2.0 percent versus about 1.7 percent among 47-51 year-olds, 1.6 percent among 52-56 year-olds, 1.5 percent among 57-61 year-olds, 1.3 percent among 62-66 year-olds, and just 1.2 percent among 67-71 year-olds. The difference may not signal a difference in involuntary job loss across age groups, since some job losers may have left the labor force rather than searched for work when they were dismissed from a job. If labor force exit is more common among older compared with younger workers, the dismissal rate across age groups might have been the same.

\section{Exits from Employment to Nonparticipation}

Figure 6 shows exit rates from employment to not-in-the-labor-force status $(E=>N)$. Results for women are displayed in the top panel; results for men are shown at the bottom. The lines in each panel track exit rates for the five oldest age groups included in Figures 4 and 5. For both women and men it is plain that exits to nonparticipation are much more common at older ages than at younger ones. Among women between 47 and 51, only about 2 percent of the

\footnotetext{
${ }^{3}$ The age breaks were chosen to highlight exit-rate differences between labor force participants eligible and not eligible for Social Security retired-worker benefits. The early entitlement age for retired-worker benefits is 62 .
} 
employed exit the labor force every month. Among employed men who are the same age, the rate of labor force exit ranges between 0.8 percent and 1.4 percent a month. In contrast, among employed women and men between 67 and 71 the monthly labor force exit rate rarely fell below 8 percent until after 2006. The striking difference in exit rates between prime-age and older age groups can be explained by retirements. After workers attain their mid-50s, they are increasingly likely to leave the workforce, either temporarily or permanently, and rely on disability or retirement pensions rather than on earned income to support themselves.

The second notable feature of Figure 6 is that exit rates from employment to nonparticipation in the older age groups have declined substantially over time, both among women and men. In contrast, there has been little change in exits to nonparticipation in younger age groups. This conclusion is strengthened when we calculate average monthly exit rates over relevant intervals of the analysis period and compare the experiences of younger and older age groups. Using the onset of recessions as significant break points, I have divided the 1994-2014 period into five subperiods. Two of these contain recessions and the first 24 months of the subsequent recovery, and the other three contain the later recovery periods of economic expansions. The first period, which extends from January 1994 through March 2001, contains the last 87 months of the 120-month 1991-2001 economic expansion. The second, extending from April 2001 through November 2003, includes the 2001 recession and the first 24 months of the ensuing recovery. The third, ranging from December 2003 through December 2007, includes the last 49 months of the 2001-2007 economic expansion. The fourth period includes the 20082009 recession plus the first 24 months of expansion during the following recovery (January 2008 through June 2011). The last period includes the later recovery months in the post-2009 expansion, July 2012 through December 2014. (Exit rates by gender and age group in all five periods are reported in Appendix Table 3.)

Figure 7 displays average exit rates from employment to nonparticipation during the three late expansion periods: 1994-2000, 2004-2007, and 2011-2014. The top panel shows average exit rates during the indicated periods for women in successive 5-year age groups, from age 2731 up to age 67-71. In each of the expansions $E=>N$ exit rates decline with age between ages 27-31 and 47-51 and then rise steeply after age 61. The lower panel in Figure 7 shows the change in exit rates between the earliest expansion, in 1994-2000, and the last one, in 2011-2014. The notable difference across age groups is the sharp fall in labor force exit rates in the three 
oldest groups. At ages under 52 there is very little change in workers' exit rate into nonparticipation. Clearly, a major contributor to higher participation rates in the oldest age groups has been the recent decline in labor force exit among employed women past age 57.

Figure 8 shows similar exit statistics for men. The pattern of change is strikingly similar to that among women. Men under 57 saw little change in their exit rate from employment to nonparticipation. In the youngest age group, below age 32, employed men experienced an increase in exits to nonparticipation. In contrast, the two oldest age groups, between 62 and 71, saw a sharp falloff in the rate of exit to nonparticipation. Older women and men who continued to hold jobs after the Great Recession were less likely to leave the labor force compared with workers the same age in the earlier economic expansions in 1994-2000 and 2004-2007. As demonstrated in Figures 7 and 8, this change in employment exit behavior stands in marked contrast to the behavior of workers in younger age groups, partly explaining the participation rate trends in Figure 1.

Figures 7 and 8 emphasize differences in exit behavior during late recovery periods. Another salient comparison emphasizes changes in exit behavior during economic slumps, that is, in recessions and the first 24 months of an economic recovery. Figure 9 shows average exit rates from employment to nonparticipation during the two slumps in our analysis period, 20012003 and 2008-2011. The top panel shows average exit rates during the indicated periods for men in 5-year age groups. In each of the expansions, $E=>N$ exit rates are noticeably higher among men past 56 compared with men in the younger age groups. The lower panel in Figure 9 shows the change in exit rates between the earlier slump, in 2001-2003, and the later one, in 2008-2011. As is the case in Figure 8, there was a sharp decline in older men's exits from employment into nonparticipation. In contrast, there was little change between 2001-2003 and 2008-2011 in exit rates among men under 57. There is a similar pattern of change across age groups among women when we compare $E=>N$ exit rates in the two slumps. Compared with exit rates in the 2001-2003 slump, those in the later slump were lower in all female age groups, but the drop was considerably bigger among women 62 and older (see top panel in Appendix Table 3a).

For workers who exit employment but remain in the labor force, the CPS questionnaire asks whether the unemployment spell began as a result of a permanent or temporary layoff or as a result of a quit. In the case of workers who leave employment without searching for work, 
however, the question is not posed. Thus, it is not clear whether people who have left employment for nonparticipation have done so a result of a dismissal or a voluntary quit. It seems plausible that many employment exits to nonparticipation, especially among older workers, are voluntary. The results in Figures 7 through 9 may indicate that in recent years employed older workers have reduced their rates of voluntary exit into nonparticipation.

The two kinds of exit from employment - into unemployment or into nonparticipation both lead to a labor force status we can refer to as “joblessness.” Figure 10 shows the implied changes in the rate of flow into joblessness between the 1994-2000 period and 2011-2014. In contrast to the younger age groups, men and women in the oldest age groups have seen a sizeable decline in their monthly rates of flow into joblessness. We see an identical pattern of change if we calculate differences between exit rates in the slumps of 2001-2003 and 2008-2011. Because so many job exits at older ages are motivated by workers' voluntary decision to retire, it seems likely that at least some of the difference in exit trends between younger and older workers is explained by the fact that more recent cohorts of aged workers are trying to delay the age at which they retire. Note that even if older workers suffered dismissal rates that are as high or higher than those experienced by younger workers, the fact that older workers ordinarily have much higher voluntary quit rates gives them more scope to reduce their rates of exit into joblessness. The results in Figures 7 - 9 show that exit rates from employment into nonparticipation have fallen more sharply among older compared with younger workers. The results in Figure 10 show that, notwithstanding the surge of flows from employment to unemployment, the overall exit rate from employment has dropped among older workers even as it has increased or remained almost unchanged in most prime-age and younger groups.

\section{Exits from Unemployment}

Since the onset of the Great Recession unemployed workers have found it much harder to find jobs. Exit rates from $U=>E$ have declined in every age group, even if we compare exits in the recent recovery period (2011-2014) with exit rates in the 2001-2003 slump (see Appendix Table 3b). Figure 11 shows the the change in exit rates between the earliest expansion, in 19942000, and the most recent one, in 2011-2014. Exit rates from unemployment to employment tend to be lower at older ages than at younger ages, especially for men. The percentage-point 
drop in $U=>E$ exit rates was also somewhat smaller among older men, though there is less evidence for this among women.

The more striking shift in exit patterns from unemployment is the sizeable drop of exits into nonparticipation, $U=>N$, among unemployed workers in older age groups. Figure 12 shows average exit rates from unemployment to nonparticipation during the three late expansion periods. The top panel shows average exit rates during the indicated periods for women in the 5year age groups. In each of the expansions $U=>N$ exit rates rise starting at about age 52 . The lower panel in Figure 12 shows the change in exit rates between the earliest expansion, in 19942000, and the most recent one, in 2011-2014. The notable difference across age groups is the sharp fall in labor force exit rates in the oldest groups. At younger ages there are much smaller changes in the rate of exit from unemployment to nonparticipation. Older workers, unlike younger ones, tended to remain in the workforce more tenaciously than their counterparts in the late 1990s. There is a similar pattern among women (see Appendix Table 3b). Exit rates from unemployment to nonparticipation fell more steeply among older women than among younger ones. The same pattern is seen when we compare exit rates in the earlier and later slumps. Among both women and men, the falloff in exits from unemployment to nonparticipation is larger among the old than the young.

\section{Exits from Nonparticipation}

Nonparticipants can enter the labor force either by beginning an active search for work ( $N=>U$ ) or obtaining a job $(N=>E)$. Either change will tend to increase the labor force participation rate, but the latter will also boost the employment-to-population rate. Since the 1990s exit rates from nonparticipation into unemployment have increased in all age groups and for both sexes (see Appendix Table 3c). However, exit rates into employment have declined for most age groups with the notable exception of the oldest ones. On balance the changes have tended to reduce flows from nonparticipation into the labor force for women under 52 and men under 37. They have tended to increase flows into the labor force for women past 52 and men older than 36.

The gap between young and old is particularly striking in labor market flows from nonparticipation into employment $(N=>E)$. Figure 13 shows women's transition rates from nonparticipation into employment in later recovery periods, by age. The top panel shows that 
$N=>E$ exit rates are higher for younger than for older workers. However, between 1994-2000 and 2011-2014 transition rates from $N=>E$ fell in every age group younger than 52 and increased in the two age groups older than 61. Changes in exits rates from nonparticipation to employment followed a similar pattern among men. The top panel in Figure 14 shows changes in men's $N=>E$ exit rates between 1994-2000 and 2011-2014, both periods of economic expansion and employment growth. The bottom panel shows changes in the same exit rates between the earlier and later slumps, in 2001-2003 and 2008-2011. Both comparisons show a similar pattern of decline in exit rates to employment. Younger age groups have experienced a much greater decline in flows from nonparticipation into paid employment. Older age groups have seen virtually no change in these flows.

\section{Controlling for the Effects of Individual Characteristics: Educational Attainment}

The analysis so far has only considered shifts in labor force transition patterns with reference to the age distribution of the population. Other individual characteristics also affect exits into employment, unemployment, and nonparticipation. One characteristic of particular significance for the elderly is schooling attainment. Gains in high school and college completion after World War II boosted educational attainment of young adults compared with older ones, but the gains in schooling eventually slowed, especially among men. Nonetheless, past gains in schooling had a major impact on the distribution of educational attainment among older Americans over the period covered by this analysis. Among adults between 65 and 69, the fraction who failed to complete high school fell from 30 percent in 1994 to 14 percent in 2011. The fraction who held a college degree increased from 15 percent to 29 percent over the same period (Burtless 2015). Changes in the schooling attainments of prime-age and younger age groups were far less dramatic.

The remainder of the paper considers how the conclusions of the previous section are affected if we account for schooling attainment to explain changes in labor force flow rates over the past two decades. To keep the comparisons manageable, I reduce the age groups considered from 10 to 5 (ages 27-34, 35-44, 45-54, 55-61, and 61-76). This still allows a direct comparison of labor force flow rates among prime-age groups, on the one hand, and the near elderly and the elderly, on the other. The relevant comparisons are between a group's exit rates in early and late periods, in particular, between the recessions in 2001 and 2008-2009 and between past 
recoveries and the recovery after the Great Recession. As in the previous section, we are examining shifts in labor market flows to account for the increase in old-age employment and labor force participation. In the previous section changes in exit rates were calculated without reference shifts that might be explained by changing educational attainment. In this section schooling attainment is included in the specification.

For ease of interpreting results, I use the linear probability model. A principal advantage of the model is that the coefficient estimates are directly interpretable. Each coefficient shows the average marginal effect of the indicator variable with which it is associated. Tables 1 through 5 present coefficient estimates for models predicting women's and men's exit rates from employment, unemployment, and nonparticipation. The coefficients are obtained with weighted least squares, where the weights are derived from the CPS longitudinal weights. ${ }^{4}$ The specification includes a straightforward seasonal adjustment: Dummy variables are included for all but one of the 12 months. The basic model includes main effects for five mutually exclusive levels of school attainment: less than a high school diploma, high school completion, some college attendance, completion of college, and post-college education. The model also includes main effects for the five age categories already mentioned plus interactions of these age categories with three periods: (a) months designated as recessionary by the NBER Business Cycle Dating Committee; (b) months in the Great Recession; and (c) months in the recovery following the Great Recession. By implication, the reference period consists of all months of economic expansion before the Great Recession. The specification permits a straightforward test of the difference between exit rates in the two recessions and between exit rates in the recovery from the Great Recession compared with the two earlier expansions.

\section{Exits from Employment}

The linear probability model estimates predicting women's exits from employment are presented in Table 1. Results in the first column predict exits to unemployment $(E=>U)$; results in the second predict exits to nonparticipation $(\mathrm{E}=>\mathrm{N})$; results in the third predict exits to joblessness (that is, either into $U$ or $N$ ). The coefficients in column 3 are the sums of the corresponding coefficients in columns 1 and 2. The main effects of educational attainment and

\footnotetext{
${ }^{4}$ In order to give equal weight to each year's labor force transitions, we normalized the weights used in our estimates so that the sum of weights was identical in each year.
} 
age on women's exits to unemployment are displayed in Figure 15. The top panel shows exit rates among 45-54 year-old women in the expansions of 1994-2000 and 2002-2007. Exit rates into unemployment are shown for women in the five educational attainment groups. In light of the large sample of observations for these estimates and the large exit-rate differences across educational groups it is hardly surprising that the differences are highly statistically significant. (More precisely, the exit rates in four of the educational groups are statistically significantly different from the exit rate of women who have some college education.) Women who are high school dropouts have an exit rate into unemployment that is more than twice that of women with high school diplomas. Women who have post-college schooling have one-third the exit rate of women whose schooling ended with high school graduation.

The bottom panel in figure 15 shows exit rates from $E=>U$ for women who have attended but failed to complete college. Entries in the chart show the variation in $E=>U$ exit rates for women in different age groups. The exit rates represent averages for the economic expansions in 1994-2000 and 2002-2007. Exits into unemployment steadily decline with a woman's age. The exit-rate differences between age groups are highly statistically significant even though they are more modest than the differences between educational attainment groups.

The last 15 rows in Table 1 show estimated coefficients on the interactions between workers’ ages and a business cycle period after 2000. In column 1, for example, the exit rate from employment to unemployment increased in the 2001 recession by 0.15 percent among women between 27 and 34 years old. That increase was statistically significant. Surprisingly, however, women in the other age groups saw little change in the recession compared with exit rates during the 1994-2000 and 2002-2007 expansions. The jump in exit rates was significantly bigger for three of the age groups in the Great Recession, especially for the two oldest groups. The bottom 5 rows in the table show differences between exit rates in the 2009-2014 recovery compared with the 1994-2000 and 2002-2007 expansions. All five age groups saw jumps in their exit rates into unemployment in the most recent recovery compared with the earlier two.

The second column in Table 1 shows estimates of factors affecting women's exits from employment into nonparticipation $(E=>N)$. Compared with exit rates in the 2001 recession, exit rates into nonparticipation fell sharply in all age groups during the Great Recession. The drop was especially large among women 62 and older. Similarly, the bottom 5 rows show a sharp decline in exit rates to nonparticipation after the Great Recession, with a sizeable drop among 
women past 62. This is consistent with the finding reported in the previous section, where there were no statistical controls for workers' educational attainment (see Figure 7). Controlling for changes in schooling attainment reduces but does not eliminate the large falloff among older women in exits from employment to nonparticipation.

The sum of exits to unemployment and to nonparticipation gives us the exit rate into joblessness (see column 3 in Table 1). The results show sizeable differences between women's

exit rates into joblessness based on their schooling attainment. Even controlling for the effects of education, however, coefficients at the bottom of the table show a notable falloff in exit rates into joblessness among women in the oldest age group, both in the Great Recession and in the recovery from that recession. Again, the finding is consistent with the result reported in the previous section, where there were no statistical controls for workers' educational attainment (see top panel of Figure 10).

Trends in exit from employment among men are similar to those among women (see Table 2). Exit rates into unemployment increased only modestly in the 2001 recession compared with rates during the 1994-2000 and 2002-2007 expansions. However, they jumped sharply in all age groups during the Great Recession and in the recovery from that recession. In the oldest age group the surge in exits to unemployment was more than offset by a notable drop in exits out of employment and into nonparticipation (see column 2 in Table 2). For men as for women the combined trends mean than the exit rate from employment to joblessness fell significantly in the oldest age group, a finding that corresponds with our result when workers' schooling attainment is not controlled (see bottom panel of Figure 10). Even though the Great Recession and its aftermath significantly increased flows of workers into unemployment, in the case of older workers the soaring layoff rate did not produce a drop in either employment or labor force participation. Older workers saw a drop in exits into nonparticipation and into joblessness.

\section{Exits from Unemployment}

Table 3 shows linear probability model estimates of predicted monthly exit rates from unemployment. The two columns on the left display results for unemployed women; the columns on the right give results for unemployed men. Coefficients reported in columns 1 and 3 refer to exits from unemployment into employment $(U=>E)$. The coefficients in columns 2 and 
4 pertain to exits into nonparticipation $(\mathrm{U}=>\mathrm{N})$. The specification, seasonal adjustment method, and weighting procedure are the same as the ones used in Tables 1 and 2.

The basic results in the top 9 rows of the table indicate major differences between exit patterns of women and men. Whereas less educated unemployed women are less likely to exit into employment compared with women who have more schooling, the opposite is true for men. The patterns of exit differences across educational groups are more similar with respect to exits into nonparticipation, but except in the oldest age group women are much more likely than men to exit the labor force from unemployment. Both for women and men, exits from unemployment into nonparticipation are much more common in the oldest age group compared with younger groups.

Mirroring the pattern displayed in Figure 11, the results in the bottom 10 rows of Table 3 show striking declines in exits from unemployment to employment in all age groups in the Great Recession and in the recovery from that recession. Exit rates into nonparticipation also dropped in most age groups. As unemployed workers remained in unemployment longer, the average length of a spell increased. Workers who report being unemployed are asked how long they have been searching for work. Even though their responses to this question do not necessarily correspond to their reported labor force status in earlier months, their answers are nonetheless indicative of their persistence and lack of success in job finding. Workers with shorter reported spells of unemployment tend to have greater success in finding work in the following month.

Figure 16 shows estimates of the relation between the reported duration of an unemployment spell, on the horizontal axis, and the probability an unemployed male worker will become employed in the following month. The top panel shows estimates based on the experiences of 27-54 year-old male workers who have some college education, though the results look similar for unemployed workers with different levels of schooling as well as for unemployed women. Results in the lower panel show employment success rates of 62-76 yearold unemployed workers who have some college education. For any given duration of an unemployment spell in progress, older workers are less successful than younger ones in landing a job.

The chart shows that workers who have only recently become unemployed have a far higher likelihood of entering employment than workers reporting lengthy unemployment spells. In part this may reflect differences in job seekers’ potential value to employers, with workers 
who have better perceived qualifications finding employment faster. However, randomized trials suggest that at least some employers use job applicants' unemployment duration as a signal of quality, and they discriminate against applicants with longer durations (Kroft et al. 2013;

Oberholzer-Gee 2008). If employer discrimination against long-time job seekers is common, then the increased duration of unemployment spells during and after the Great Recession may have directly contributed to the falling reemployment rates of the unemployed. At any rate, the drop in exits from unemployment to employment increased the durations of unemployment spells, and the increase in turn contributed to workers' declining success in finding employment.

The results in the bottom rows of columns 2 and 4 show changes in exit flows from unemployment to nonparticipation. A prominent difference across age groups is the sharp fall in labor force exit rates in the oldest groups, especially in the recovery from the Great Recession. At younger ages there are smaller changes in the rate of exit from unemployment to nonparticipation. Older workers, more so than younger ones, tended to remain in the workforce more persistently than their counterparts in the late 1990s. The estimated difference in the behavior between the young and the old seems more modest when educational attainment is controlled in the specification, indicating that some of the extra persistence observed in the previous section is traceable to improvements in the educational credentials of older unemployed workers.

\section{Exits from Nonparticipation}

Tables 4 and 5 show estimates of the factors affecting exits from not-in-the-labor-force status to employment ( $N=>E$ ), to unemployment ( $N=>U$ ), and into the labor force, that is, into either employment or unemployment $(N=>L F)$. Coefficients in the top rows of the tables indicate that nonparticipating women and men who have more schooling are significantly more likely to enter employment and the labor force than nonparticipants the same age who have less schooling. There are also sizeable differences in flows into employment and into the labor force by age, with older workers far less likely to shift from nonparticipation into a job or into the labor force.

The results in the tables are consistent with those presented in the previous section in showing that exit rates from nonparticipation into employment have declined in the most recent expansion compared with earlier expansions. However, the drop has been much smaller among 
the oldest groups compared with the younger ones. Thus, even controlling for nonparticipants' educational credentials we still see a difference between the age groups that has tended to boost employment more among aged nonparticipants than among the nonaged.

The results in the third columns of Tables 4 and 5 show a less consistent pattern of change in exit rates from nonparticipation into the labor force. In the case of women, it is plainly the case that nonparticipants in the two oldest age groups have seen an increase in their probability of entering the labor force whereas the three younger groups have all seen a decline. This change in exit patterns tends to boost older women's participation rates compared with those of older women in past recessions and recoveries. In contrast, nonparticipating women in younger age groups have experienced a decline in their transition rate into the labor force compared with earlier cohorts. For men, changes in labor force entry patterns among nonparticipants have not boosted the participation rate of older groups compared with younger ones. Among nonparticipating men between 35 and 54, the drop in the exit rate into employment has been more than counterbalanced by an increase in the exit rate into unemployment. As a result, there has been a modest but statistically significant increase in nonparticipants' rate of entry into the labor force. We see a similar pattern among men in late middle age (55-61) but not among nonparticipating men past 62 , who have experienced almost no change in their entry rate into the labor force, controlling for their educational attainment.

\section{Conclusion}

Unlike prime-age and younger Americans, who have experienced declines in employment and labor force participation since the onset of the Great Recession, Americans over 60 have seen their employment and labor force participation rates increase. This paper attempts to help understand this development using matched CPS interview data that allow us to track monthly changes in the labor force status of young and old Americans. Unlike the published BLS gross flow data, which do not distinguish between flows in different age groups or attempt to control for shifts in the age structure of the population, I created a data file that identifies the age and other individual characteristics of CPS respondents, calculating monthly labor force status changes for those respondents whose monthly interviews can be matched in successive months. The resulting file permits us to analyze labor force transitions by age and other characteristics, but it has not been subject to BLS procedures that make the estimated labor 
market flows consistent with the monthly cross-sectional estimates of Americans' labor force status. As a result, the estimates of transition probabilities cannot be used to generate accurate monthly predictions of participation, employment, or unemployment rates within an age group.

What matters for understanding recent labor force trends, however, are changes in average flow rates over time. Under the assumption that biases in accurately determining flow rates are roughly constant over time, we can use unadjusted estimates of the flows to compare transition rates across age groups, and within a given age group, over time. The initial tabulations show, not surprisingly, wide differences in labor force transition patterns across age groups. Transitions from employment to unemployment, for example, tend to be less common for older workers than for prime-age and younger workers. In contrast, transition rates from employment to nonparticipation increase steeply with age after workers reach their middle 50s.

What is crucial for understanding the surprising strength of old-age labor force participation and employment, however, is the change in transition probabilities within and across age groups. This paper documents several shifts that help explain the increase in old-age employment and labor force participation:

- Like workers in all age groups, workers in older groups saw a surge in monthly transitions from employment to unemployment, both in the Great Recession and in the recovery that followed.

- Unlike workers in prime-age and younger groups, however, older workers also saw a sizeable decline in exits to nonparticipation. While the surge in exits from employment to unemployment tended to reduce the employment rate of all age groups, the drop in employment exits to nonparticipation among the aged tended to hold up labor force participation rates and employment rates among the elderly compared with the nonelderly. Among the elderly, but not the nonelderly, the $E=>N$ exit rate fell more than the $E=>U$ exit rate increased.

- The Great Recession and slow recovery from that recession made it harder for the unemployed to transition into employment. Exit rates from unemployment into employment fell sharply in all age groups, old and young.

- In contrast to the unemployed in younger age groups, however, the unemployed in the oldest age groups also saw a drop in their exits to nonparticipation. Compared with the nonaged, this tended to help maintain the labor force participation rates of the old. 
Flows from out-of-the-labor-force status into employment have declined for most age groups, but they have declined the least or have actually increased modestly among older nonparticipants.

These interpretations of labor force flow data are based on simple tabulations of exit rates within age groups and the changes in these exit rates over time. It is also possible to use the microdata to analyze the effects of other characteristics, such as educational attainment, on labor force flows. This additional analysis suggests that some of the favorable trends seen in the older age groups are likely to be explained, in part, by the substantial improvement in older Americans' educational attainment over the period covered by the analysis. Better-educated older people tend to have lower monthly flows from employment into unemployment and nonparticipation, and they have higher monthly flows from nonparticipant into employment compared with less educated workers.

Like all other age groups, aged workers experienced considerable harm as a result of the surge in layoffs in 2008-2010 and the disappointingly slow increase in net new jobs created after the Great Recession. The layoffs greatly increased the ranks of the unemployed. The slow growth in employment during the recovery increased the amount of time required for unemployed workers to find jobs. A big difference between the old and the young is that a very large share of older workers' exits from employment is voluntary, both in recessions and in expansions. By reducing their high rates of voluntary exit from employment or from the labor force, older workers have wide scope to maintain or even increase their employment and participations, even in the face of exceptional job market distress. 


\section{References}

Burtless, Gary. 2015. "Trends in the Well-Being of the Aged and Their Prospects through 2030." Forum for Health Economics and Policy 18(2): 97-118.

Frazis, Harley J., Edwin L. Robison, Thomas D. Evans, and Martha A. Duff. 2005. "Estimating Gross Flows Consistent with Stocks in the CPS.” Monthly Labor Review 128(9): 3-9.

Ilg, Randy. 2005. “Analyzing CPS Data Using Gross Flows.” Monthly Labor Review 128(9): 10-18.

Kosanovich, Karen and Eleni Theodossiou Sherman. 2015. Trends in Long-Term Unemployment. Washington, DC: U.S. Bureau of Labor Statistics. Available at: http://www.bls.gov/spotlight/2015/long-term-unemployment/pdf/long-termunemployment.pdf.

Kroft, Kory, Fabian Lange and Matthew J. Notowidigdo. 2013. “Duration Dependence and Labor Market Conditions: Evidence from a Field Experiment.” Quarterly Journal of Economics 128(3): 1123-1167.

Madrian, Brigitte C. and Lars John Lefgren. 1999. “A Note on Longitudinally Matching Current Population Survey (CPS) Respondents.” NBER Technical Working Paper 0247. Cambridge, MA: National Bureau of Economic Research.

Oberholzer-Gee, Felix. 2008. “Nonemployment Stigma as Rational Herding: A Field Experiment.” Journal of Economic Behavior \& Organization 65(1): 30-40.

U.S. Council of Economic Advisers. 2014. The Labor Force Participation Rate since 2007: Causes and Policy Implications. Washington, DC: Executive Office of the President. Available at: https://www.whitehouse.gov/sites/default/files/docs/labor_force_participation_report.pdf. 
Table 1. Linear Probability Model of Women's Exit from Employment in the CPS Matched Records File, 1994-2014

\begin{tabular}{|c|c|c|c|c|c|c|}
\hline \multirow{3}{*}{ Constant } & \multirow{2}{*}{\multicolumn{2}{|c|}{$\begin{array}{c}E=>U \\
(1) \\
\end{array}$}} & \multirow{2}{*}{\multicolumn{2}{|c|}{$\begin{array}{r}E=>N \\
(2) \\
\end{array}$}} & \multirow{2}{*}{\multicolumn{2}{|c|}{$\begin{array}{c}\mathrm{E}=> \\
\text { Joblessness } \\
(3) \\
\end{array}$}} \\
\hline & & & & & & \\
\hline & 0.0061 & "*** & 0.0134 & (*** & 0.0195 & $* * *$ \\
\hline \multicolumn{7}{|l|}{ Educational attainment: } \\
\hline Less than high school & 0.0104 & $* * *$ & 0.0266 & $* * *$ & 0.0369 & $* * *$ \\
\hline High school diploma & 0.0014 & $* * *$ & 0.0068 & $* * *$ & 0.0082 & $* * *$ \\
\hline Some college & \multicolumn{6}{|c|}{ Reference educational attainment group } \\
\hline College completion & -0.0025 & $* * *$ & -0.0014 & $* * *$ & -0.0038 & $* * *$ \\
\hline Post-college schooling & -0.0037 & $* * *$ & -0.0051 & $* * *$ & -0.0087 & $* * *$ \\
\hline \multicolumn{7}{|l|}{ Main age effect: } \\
\hline Age 27-34 & 0.0036 & $* * *$ & 0.0137 & $* * *$ & 0.0173 & $* * *$ \\
\hline Age 35-44 & 0.0019 & $* * *$ & 0.0033 & $* * *$ & 0.0052 & $* * *$ \\
\hline Age 45-54 & \multicolumn{5}{|c|}{ Reference age group } & \\
\hline Age 55-61 & -0.0006 & $* * *$ & 0.0083 & $* * *$ & 0.0077 & $* * *$ \\
\hline Age 62-76 & -0.0011 & $* * *$ & 0.0541 & $* * *$ & 0.0530 & $* * *$ \\
\hline \multicolumn{7}{|c|}{ Added age effect in recessions: } \\
\hline Age 27-34 & 0.0015 & $* * *$ & -0.0033 & $* * *$ & -0.0018 & \\
\hline Age 35-44 & 0.0001 & & 0.0007 & & 0.0008 & \\
\hline Age 45-54 & 0.0005 & & 0.0022 & $* * *$ & 0.0028 & $* * *$ \\
\hline Age 55-61 & -0.0005 & & 0.0025 & $*$ & 0.0020 & \\
\hline Age 62-76 & -0.0008 & & 0.0033 & $*$ & 0.0024 & \\
\hline \multicolumn{7}{|c|}{ Added age effect in Great Recession: } \\
\hline Age 27-34 & 0.0001 & & -0.0038 & $* * *$ & -0.0037 & $* * *$ \\
\hline Age 35-44 & 0.0012 & $* *$ & -0.0023 & $* *$ & -0.0011 & \\
\hline Age 45-54 & 0.0008 & & -0.0027 & $* * *$ & -0.0019 & $*$ \\
\hline Age 55-61 & 0.0035 & $* * *$ & -0.0047 & $* * *$ & -0.0011 & \\
\hline Age 62-76 & 0.0040 & $* * *$ & -0.0160 & $* * *$ & -0.0120 & $* * *$ \\
\hline \multicolumn{7}{|c|}{ Added age effect in 2009-2014 recovery: } \\
\hline Age 27-34 & 0.0018 & $* * *$ & -0.0078 & $* * *$ & -0.0060 & $* * *$ \\
\hline Age 35-44 & 0.0019 & $* * *$ & -0.0014 & $* * *$ & 0.0005 & \\
\hline Age 45-54 & 0.0026 & $* * *$ & -0.0009 & $* * *$ & 0.0017 & $* * *$ \\
\hline Age 55-61 & 0.0015 & $* * *$ & -0.0042 & $* * *$ & -0.0026 & $* * *$ \\
\hline Age 62-76 & 0.0022 & $* * *$ & -0.0158 & $* * *$ & -0.0136 & $* * *$ \\
\hline \multicolumn{7}{|l|}{ Seasonal adjustment } \\
\hline No. of observations: & & & $4,230,30$ & & & \\
\hline
\end{tabular}

Notes: Recessions include months designated as such by the NBER Business Cycle Dating Committee in 2001 and in 2008-2009. The Great Recession is the later recession. The 2009-2014 recovery includes all months following the Great Recession. Estimates are obtained using weighted least squares. ***, **, and * indicate statistical significance at the 1 percent, 5 percent, and 10 percent significance levels, respectively. 
Table 2. Linear Probability Model of Men's Exit from Employment in the CPS Matched Records File, 1994-2014

\begin{tabular}{|c|c|c|c|c|c|c|}
\hline \multirow{3}{*}{$\begin{array}{l}\text { Constant } \\
\end{array}$} & \multicolumn{2}{|c|}{$\mathrm{E}=>\mathrm{U}$} & \multicolumn{2}{|l|}{$\mathrm{E}=>\mathrm{N}$} & \multicolumn{2}{|c|}{$\begin{array}{c}E=> \\
\text { Joblessness }\end{array}$} \\
\hline & \multicolumn{2}{|l|}{$(1)$} & \multicolumn{2}{|l|}{$(2)$} & \multicolumn{2}{|c|}{$(3)$} \\
\hline & 0.0082 & $* * *$ & 0.0076 & $* * *$ & 0.0158 & $* * *$ \\
\hline \multicolumn{7}{|l|}{ Educational attainment: } \\
\hline Less than high school & 0.0127 & $* * *$ & 0.0134 & $* * *$ & 0.0262 & $* * *$ \\
\hline High school diploma & 0.0042 & $* * *$ & 0.0028 & $* * *$ & 0.0069 & $* * *$ \\
\hline Some college & \multicolumn{6}{|c|}{ Reference educational attainment group } \\
\hline College completion & -0.0041 & $* * *$ & -0.0029 & $* * *$ & -0.0070 & $* * *$ \\
\hline Post-college schooling & -0.0058 & $* * *$ & -0.0050 & $* * *$ & -0.0108 & $* * *$ \\
\hline \multicolumn{7}{|l|}{ Main age effect: } \\
\hline Age 27-34 & 0.0037 & $* * *$ & 0.0015 & $* * *$ & 0.0051 & $* * *$ \\
\hline Age 35-44 & 0.0020 & $* * *$ & -0.0009 & $* * *$ & 0.0011 & $* * *$ \\
\hline Age 45-54 & \multicolumn{5}{|c|}{ Reference age group } & \\
\hline Age 55-61 & -0.0012 & $* * *$ & 0.0084 & $* * *$ & 0.0071 & $* * *$ \\
\hline Age 62-76 & -0.0024 & $* * *$ & 0.0695 & $* * *$ & 0.0672 & $* * *$ \\
\hline \multicolumn{7}{|c|}{ Added age effect in recessions: } \\
\hline Age 27-34 & -0.0005 & & 0.0005 & & 0.0001 & \\
\hline Age 35-44 & 0.0013 & $* *$ & 0.0000 & & 0.0013 & $*$ \\
\hline Age 45-54 & 0.0011 & $* *$ & 0.0019 & $* * *$ & 0.0030 & $* * *$ \\
\hline Age 55-61 & 0.0001 & & 0.0030 & $* * *$ & 0.0032 & $* *$ \\
\hline Age 62-76 & 0.0009 & & -0.0056 & $* * *$ & -0.0047 & $* * *$ \\
\hline \multicolumn{7}{|c|}{ Added age effect in Great Recession: } \\
\hline Age 27-34 & 0.0076 & $* * *$ & -0.0004 & & 0.0072 & $* * *$ \\
\hline Age 35-44 & 0.0036 & $* * *$ & 0.0006 & & 0.0042 & $* * *$ \\
\hline Age 45-54 & 0.0027 & $* * *$ & -0.0013 & $*$ & 0.0015 & \\
\hline Age 55-61 & 0.0036 & $* * *$ & -0.0028 & $* *$ & 0.0008 & \\
\hline Age 62-76 & 0.0021 & $*$ & -0.0161 & $* * *$ & -0.0139 & $* * *$ \\
\hline \multicolumn{7}{|c|}{$\begin{array}{l}\text { Added age effect in 2009-2014 } \\
\text { recovery: }\end{array}$} \\
\hline Age 27-34 & 0.0045 & $* * *$ & 0.0017 & $* * *$ & 0.0062 & $* * *$ \\
\hline Age 35-44 & 0.0030 & $* * *$ & 0.0010 & $* * *$ & 0.0040 & $* * *$ \\
\hline Age 45-54 & 0.0039 & $* * *$ & 0.0012 & $* * *$ & 0.0051 & $* * *$ \\
\hline Age 55-61 & 0.0037 & $* * *$ & -0.0005 & & 0.0032 & $* * *$ \\
\hline Age 62-76 & 0.0043 & $* * *$ & -0.0275 & $* * *$ & -0.0232 & $* * *$ \\
\hline \multicolumn{7}{|l|}{ Seasonal adjustment } \\
\hline No. of observations: & & & $4,682,549$ & & & \\
\hline
\end{tabular}

Notes: Recessions include months designated as such by the NBER Business Cycle Dating Committee in 2001 and in 2008-2009. The Great Recession is the later recession. The 2009-2014 recovery includes all months following the Great Recession. Estimates are obtained using weighted least squares. ***, **, and * indicate statistical significance at the 1 percent, 5 percent, and 10 percent significance levels, respectively. 
Table 3. Linear Probability Model of Exit from Unemployment in the CPS Matched Records File, 1994-2014

\begin{tabular}{|c|c|c|c|c|c|c|c|c|}
\hline & \multicolumn{4}{|c|}{ Women } & \multicolumn{4}{|c|}{ Men } \\
\hline & \multirow{2}{*}{\multicolumn{2}{|c|}{$\begin{array}{c}\mathrm{U}=>\mathrm{E} \\
(1)\end{array}$}} & \multirow{2}{*}{\multicolumn{2}{|c|}{$\begin{array}{c}\mathrm{U}=>\mathrm{N} \\
(2)\end{array}$}} & \multirow{2}{*}{\multicolumn{2}{|c|}{$\begin{array}{c}\mathrm{U}=>\mathrm{E} \\
(3)\end{array}$}} & \multirow{2}{*}{\multicolumn{2}{|c|}{$\begin{array}{c}\mathrm{U}=>\mathrm{N} \\
(4)\end{array}$}} \\
\hline & & & & & & & & \\
\hline Constant & 0.2254 & $* * *$ & 0.2159 & $* * *$ & 0.2623 & $* * *$ & 0.1356 & $* * *$ \\
\hline \multicolumn{9}{|l|}{ Educational attainment: } \\
\hline Less than high school & -0.0366 & $* * *$ & 0.0889 & $* * *$ & 0.0293 & $* * *$ & 0.0249 & $* * *$ \\
\hline High school diploma & -0.0136 & $* * *$ & 0.0333 & $* * *$ & 0.0082 & $* * *$ & 0.0082 & $* * *$ \\
\hline Some college & \multicolumn{7}{|c|}{ Reference educational attainment group } & \\
\hline College completion & 0.0291 & $* * *$ & -0.0210 & $* * *$ & -0.0082 & $* * *$ & -0.0275 & $* * *$ \\
\hline Post-college schooling & 0.0494 & $* * *$ & -0.0246 & $* * *$ & -0.0143 & $* * *$ & -0.0184 & $* * *$ \\
\hline \multicolumn{9}{|l|}{ Main age effect: } \\
\hline Age 27-34 & 0.0225 & $* * *$ & 0.0117 & $* * *$ & 0.0503 & $* * *$ & -0.0058 & $*$ \\
\hline Age 35-44 & 0.0153 & $* * *$ & -0.0005 & & 0.0268 & $* * *$ & -0.0065 & $* *$ \\
\hline Age 45-54 & \multicolumn{7}{|c|}{ Reference age group } & \\
\hline Age 55-61 & 0.0002 & & -0.0023 & & -0.0271 & $* * *$ & 0.0465 & $* * *$ \\
\hline Age 62-76 & -0.0225 & $* * *$ & 0.1220 & $* * *$ & -0.0661 & $* * *$ & 0.2109 & $* * *$ \\
\hline \multicolumn{9}{|c|}{ Added age effect in recessions: } \\
\hline Age 27-34 & 0.0248 & $* *$ & -0.0070 & & 0.0345 & $* * *$ & 0.0125 & \\
\hline Age $35-44$ & 0.0143 & & 0.0107 & & 0.0302 & $* * *$ & -0.0222 & $* *$ \\
\hline Age 45-54 & 0.0570 & $* * *$ & -0.0450 & $* * *$ & 0.0312 & $* *$ & -0.0006 & \\
\hline Age 55-61 & 0.0393 & $*$ & 0.0212 & & 0.0134 & & -0.0172 & \\
\hline Age 62-76 & 0.0417 & & 0.0208 & & 0.0471 & $*$ & -0.0298 & \\
\hline \multicolumn{9}{|c|}{ Added age effect in Great Recession: } \\
\hline Age 27-34 & -0.0857 & $* * *$ & -0.0024 & & -0.1071 & $* * *$ & -0.0189 & $*$ \\
\hline Age 35-44 & -0.0666 & $* * *$ & -0.0281 & $* *$ & -0.0921 & $* * *$ & 0.0081 & \\
\hline Age $45-54$ & -0.1097 & $* * *$ & 0.0028 & & -0.0842 & $* * *$ & -0.0253 & $* *$ \\
\hline Age 55-61 & -0.1073 & $* * *$ & -0.0465 & $* *$ & -0.0526 & $* *$ & -0.0237 & \\
\hline Age 62-76 & -0.0826 & $* * *$ & -0.0574 & $*$ & -0.0760 & $* * *$ & -0.0520 & $* *$ \\
\hline \multicolumn{9}{|c|}{ Added age effect in 2009-2014 recovery: } \\
\hline Age 27-34 & -0.1004 & $* * *$ & -0.0107 & $* * *$ & -0.1127 & $* * *$ & 0.0009 & \\
\hline Age 35-44 & -0.0904 & $* * *$ & -0.0193 & $* * *$ & -0.0899 & $* * *$ & -0.0144 & $* * *$ \\
\hline Age 45-54 & -0.0811 & $* * *$ & -0.0353 & $* * *$ & -0.0863 & $* * *$ & -0.0126 & $* * *$ \\
\hline Age 55-61 & -0.0938 & $* * *$ & -0.0261 & $* * *$ & -0.0818 & $* * *$ & -0.0347 & $* * *$ \\
\hline Age 62-76 & -0.0867 & $* * *$ & -0.0541 & $* * *$ & -0.0595 & $* * *$ & -0.0738 & $* * *$ \\
\hline \multicolumn{9}{|l|}{ Seasonal adjustment } \\
\hline No. of observations: & & & 193,979 & & & & 220,394 & \\
\hline
\end{tabular}

Notes: Recessions include months designated as such by the NBER Business Cycle Dating Committee in 2001 and in 2008-2009. The Great Recession is the later recession. The 2009-2014 recovery includes all months following the Great Recession. Estimates are obtained using weighted least squares. ***, **, and * indicate statistical significance at the 1 percent, 5 percent, and 10 percent significance levels, respectively. 
Table 4. Linear Probability Model of Women's Exit from Nonparticipation in the Labor Force in the CPS Matched Records File, 1994-2014

\begin{tabular}{|c|c|c|c|c|c|c|}
\hline \multirow{3}{*}{ Constant } & \multirow{2}{*}{\multicolumn{2}{|c|}{$\begin{array}{c}\text { NILF }=>E \\
(1)\end{array}$}} & \multirow{2}{*}{\multicolumn{2}{|c|}{$\begin{array}{c}\text { NILF }=>U \\
(2)\end{array}$}} & \multirow{2}{*}{\multicolumn{2}{|c|}{$\begin{array}{c}\text { NILF => LF } \\
(3)\end{array}$}} \\
\hline & & & & & & \\
\hline & 0.0604 & $* * *$ & 0.0265 & $* * *$ & 0.0869 & $* * *$ \\
\hline \multicolumn{7}{|l|}{ Educational attainment: } \\
\hline Less than high school & -0.0160 & $* * *$ & -0.0028 & $* * *$ & -0.0188 & $* * *$ \\
\hline High school diploma & -0.0061 & $* * *$ & -0.0029 & $* * *$ & -0.0090 & $* * *$ \\
\hline Some college & \multicolumn{6}{|c|}{ Reference educational attainment group } \\
\hline College completion & 0.0051 & $* * *$ & -0.0073 & $* * *$ & -0.0022 & $* * *$ \\
\hline Post-college schooling & 0.0140 & $* * *$ & -0.0038 & $* * *$ & 0.0103 & $* * *$ \\
\hline \multicolumn{7}{|l|}{ Main age effect: } \\
\hline Age 27-34 & 0.0154 & $* * *$ & 0.0160 & $* * *$ & 0.0314 & $* * *$ \\
\hline Age 35-44 & 0.0130 & $* * *$ & 0.0095 & $* * *$ & 0.0225 & $* * *$ \\
\hline Age 45-54 & \multicolumn{5}{|c|}{ Reference age group } & \\
\hline Age 55-61 & -0.0222 & $* * *$ & -0.0112 & $* * *$ & -0.0334 & $* * *$ \\
\hline Age 62-76 & -0.0446 & $* * *$ & -0.0200 & $* * *$ & -0.0646 & $* * *$ \\
\hline \multicolumn{7}{|c|}{ Added age effect in recessions: } \\
\hline Age 27-34 & 0.0040 & $* *$ & 0.0018 & & 0.0058 & $* *$ \\
\hline Age 35-44 & -0.0006 & & -0.0027 & $* *$ & -0.0034 & $*$ \\
\hline Age 45-54 & 0.0017 & & -0.0027 & $* *$ & -0.0010 & \\
\hline Age $55-61$ & -0.0009 & & -0.0020 & & -0.0028 & \\
\hline Age 62-76 & -0.0020 & $*$ & -0.0004 & & -0.0024 & * \\
\hline \multicolumn{7}{|c|}{ Added age effect in Great Recession: } \\
\hline Age 27-34 & -0.0145 & $* * *$ & 0.0022 & & -0.0123 & $* * *$ \\
\hline Age 35-44 & -0.0120 & $* * *$ & 0.0068 & $* * *$ & -0.0051 & $* *$ \\
\hline Age $45-54$ & -0.0114 & $* * *$ & 0.0079 & $* * *$ & -0.0035 & \\
\hline Age 55-61 & 0.0012 & & 0.0066 & $* * *$ & 0.0078 & $* * *$ \\
\hline Age 62-76 & 0.0026 & $* *$ & 0.0022 & $* *$ & 0.0048 & $* * *$ \\
\hline \multicolumn{7}{|c|}{ Added age effect in 2009-2014 recovery: } \\
\hline Age 27-34 & -0.0192 & $* * *$ & 0.0122 & $* * *$ & -0.0070 & $* * *$ \\
\hline Age 35-44 & -0.0206 & $* * *$ & 0.0089 & $* * *$ & -0.0117 & $* * *$ \\
\hline Age 45-54 & -0.0127 & $* * *$ & 0.0099 & $* * *$ & -0.0027 & $* * *$ \\
\hline Age 55-61 & -0.0048 & $* * *$ & 0.0084 & $* * *$ & 0.0036 & $* * *$ \\
\hline Age 62-76 & -0.0005 & & 0.0033 & $* * *$ & 0.0027 & $* * *$ \\
\hline \multicolumn{7}{|l|}{ Seasonal adjustment } \\
\hline No. of observations: & & & $2,448,157$ & & & \\
\hline
\end{tabular}

Notes: Recessions include months designated as such by the NBER Business Cycle Dating Committee in 2001 and in 2008-2009. The Great Recession is the later recession. The 2009-2014 recovery includes all months following the Great Recession. Estimates are obtained using weighted least squares. ***, **, and * indicate statistical significance at the 1 percent, 5 percent, and 10 percent significance levels, respectively. 
Table 5. Linear Probability Model of Men's Exit from Nonparticipation in the Labor Force in the CPS Matched Records File, 1994-2014

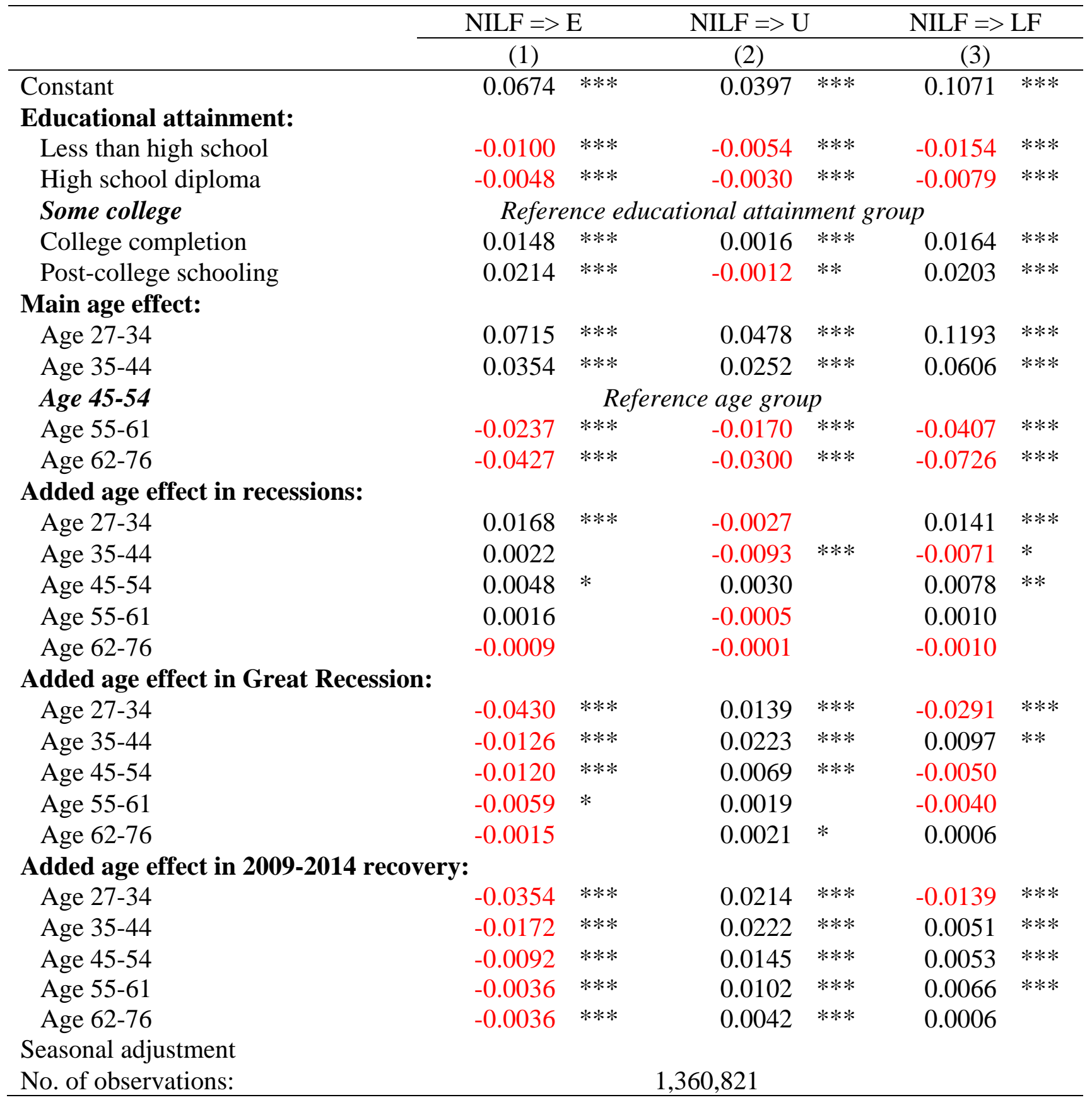

Notes: Recessions include months designated as such by the NBER Business Cycle Dating Committee in 2001 and in 2008-2009. The Great Recession is the later recession. The 2009-2014 recovery includes all months following the Great Recession. Estimates are obtained using weighted least squares. ***, **, and * indicate statistical significance at the 1 percent, 5 percent, and 10 percent significance levels, respectively. 
Appendix Table 1. Matched CPS Records Used in Analysis, by Period, Gender, and Initial Labor Force Status

\begin{tabular}{|c|c|c|c|c|c|c|c|c|}
\hline \multirow[b]{3}{*}{ Years * } & \multicolumn{6}{|c|}{ Labor force status in first month } & \multirow{2}{*}{\multicolumn{2}{|c|}{ Total }} \\
\hline & \multicolumn{2}{|c|}{ Employed } & \multicolumn{2}{|c|}{ Unemployed } & \multicolumn{2}{|c|}{ Not in labor force } & & \\
\hline & Men & Women & Men & Women & Men & Women & Men & Women \\
\hline 1994-2000 & $1,491,505$ & $1,314,698$ & 52,401 & 48,949 & 411,865 & 786,845 & $1,955,771$ & $2,150,492$ \\
\hline 2001-2003 & 635,589 & 576,063 & 27,335 & 23,599 & 172,963 & 323,906 & 835,887 & 923,568 \\
\hline 2004-2007 & 959,638 & 873,425 & 34,946 & 32,862 & 268,319 & 481,313 & $1,262,903$ & $1,387,600$ \\
\hline 2008-2011 & 811,889 & 751,187 & 58,824 & 45,670 & 245,694 & 421,341 & $1,116,407$ & $1,218,198$ \\
\hline 2011-2014 & 783,576 & 714,629 & 46,871 & 42,887 & 261,869 & 434,546 & $1,092,316$ & $1,192,062$ \\
\hline 1994-2014 & 4,682,197 & $4,230,002$ & 220,377 & 193,967 & $1,360,710$ & $2,447,951$ & $6,263,284$ & $6,871,920$ \\
\hline
\end{tabular}

* Year intervals are selected to correspond with late recovery periods and recessions plus the first 24 months of the following recovery: "1994-2000" includes Feb. 1994 to Mar. 2001; "2001-2003" includes Apr. 2001-Nov. 2003; "2004-2007" includes Dec. 2003-Dec. 2007; "2008-2011" includes Jan. 2008-Jun. 2011; and "2011-2014" includes Jul. 2011-Dec. 2014. See text.

Appendix Table 2. Matched CPS Records, by Age, Gender, and Initial Labor Force Status

\begin{tabular}{|c|c|c|c|c|c|c|}
\hline \multirow[b]{3}{*}{ Ages * } & \multicolumn{6}{|c|}{ Labor force status in first month } \\
\hline & \multicolumn{2}{|c|}{ Employed } & \multicolumn{2}{|c|}{ Unemployed } & \multicolumn{2}{|c|}{ Not in labor force } \\
\hline & Men & Women & Men & Women & Men & Women \\
\hline $27-31$ & 588,379 & 526,715 & 34,989 & 32,037 & 50,127 & 177,109 \\
\hline $32-36$ & 650,213 & 571,356 & 32,143 & 30,711 & 48,663 & 195,552 \\
\hline $37-41$ & 697,123 & 631,110 & 31,685 & 29,812 & 56,475 & 193,396 \\
\hline $42-46$ & 708,573 & 659,526 & 31,184 & 28,033 & 68,309 & 181,436 \\
\hline $47-51$ & 676,279 & 631,865 & 29,623 & 25,375 & 85,827 & 186,043 \\
\hline $52-56$ & 570,307 & 526,812 & 25,209 & 20,660 & 110,962 & 204,896 \\
\hline $57-61$ & 416,784 & 373,551 & 19,036 & 14,798 & 155,717 & 248,472 \\
\hline $62-66$ & 220,486 & 188,517 & 9,942 & 7,505 & 258,156 & 341,867 \\
\hline $67-71$ & 102,436 & 82,865 & 4,590 & 3,519 & 275,539 & 369,160 \\
\hline $72-76$ & 51,617 & 37,685 & 1,976 & 1,517 & 250,935 & 350,020 \\
\hline $27-76$ & $4,682,197$ & $4,230,002$ & 220,377 & 193,967 & $1,360,710$ & $2,447,951$ \\
\hline
\end{tabular}

* Age in first month of matched CPS records. 
Appendix Table 3a. Average Exit Rates from Employment in Indicated Periods, by Sex and Age, 1994-2014

Percent

\begin{tabular}{lllllllll}
\hline \multicolumn{1}{c}{ Age group } \\
\hline $27-31$ & $32-36$ & $37-41$ & $42-46$ & $47-51$ & $52-56$ & $57-61$ & $62-66$ & $67-71$ \\
\hline
\end{tabular}

Women

Period *

1994-2000

2001-2003

2004-2007

2008-2011

2011-2014

Change:

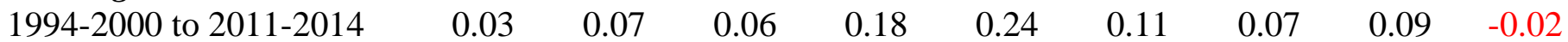

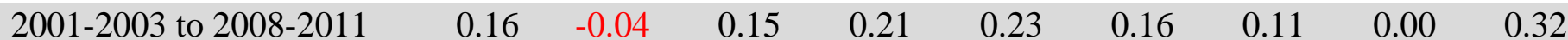

Employed $=>$ NILF

\begin{tabular}{llllllllll}
\hline $1994-2000$ & 2.66 & 2.49 & 2.22 & 1.90 & 2.02 & 2.48 & 3.56 & 6.73 & 9.83 \\
$2001-2003$ & 3.05 & 2.89 & 2.51 & 2.19 & 2.08 & 2.58 & 3.10 & 6.14 & 8.72 \\
$2004-2007$ & 2.99 & 2.79 & 2.44 & 2.14 & 2.00 & 2.21 & 3.09 & 5.51 & 8.31 \\
$2008-2011$ & 2.48 & 2.44 & 2.06 & 1.97 & 1.88 & 1.98 & 2.74 & 4.53 & 7.54 \\
$2011-2014$ & 2.59 & 2.45 & 2.30 & 2.09 & 1.93 & 2.03 & 2.53 & 4.88 & 7.37
\end{tabular}

Change:

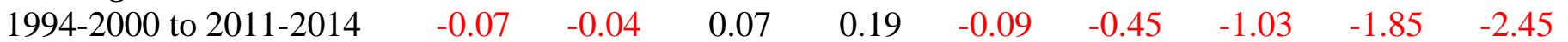

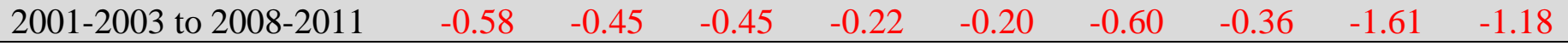

\section{Men}

Employed $=>$ Unemployed

$\begin{array}{llllllllll}1994-2000 & 1.36 & 1.16 & 1.06 & 1.02 & 0.87 & 0.85 & 0.79 & 0.71 & 0.88 \\ 2001-2003 & 1.55 & 1.37 & 1.30 & 1.15 & 0.97 & 0.98 & 0.96 & 0.88 & 0.88 \\ 2004-2007 & 1.53 & 1.18 & 1.08 & 0.97 & 0.89 & 0.88 & 0.80 & 0.82 & 0.72 \\ 2008-2011 & 2.17 & 1.86 & 1.68 & 1.58 & 1.44 & 1.27 & 1.24 & 1.05 & 1.09 \\ 2011-2014 & 1.63 & 1.41 & 1.22 & 1.21 & 1.21 & 1.06 & 1.09 & 0.95 & 0.94\end{array}$

\section{Change:}

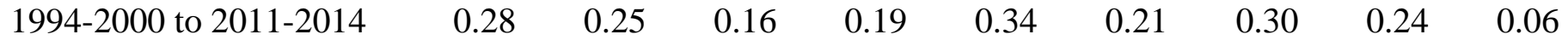

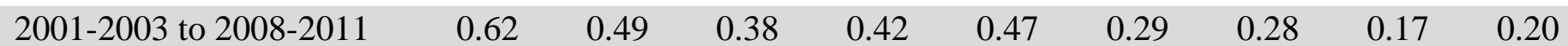

\begin{tabular}{lrrrrrrrrr} 
& \multicolumn{10}{c}{ Employed => NILF } \\
1994-2000 & 1.10 & 0.93 & 0.89 & 0.85 & 0.94 & 1.29 & 2.18 & 6.13 & 9.55 \\
$2001-2003$ & 1.32 & 1.15 & 1.03 & 0.95 & 1.05 & 1.42 & 2.29 & 5.19 & 8.43 \\
$2004-2007$ & 1.42 & 1.07 & 1.01 & 0.99 & 1.07 & 1.32 & 2.00 & 4.76 & 8.16 \\
$2008-2011$ & 1.37 & 1.11 & 0.95 & 1.01 & 1.08 & 1.33 & 2.05 & 3.87 & 7.15 \\
$2011-2014$ & 1.52 & 1.12 & 1.04 & 1.02 & 1.13 & 1.34 & 1.84 & 3.76 & 6.88 \\
ange: & & & & & & & & & \\
-2000 to 2011-2014 & 0.42 & 0.19 & 0.15 & 0.17 & 0.19 & 0.05 & -0.34 & -2.37 & -2.67 \\
-2003 to 2008-2011 & 0.05 & -0.03 & -0.07 & 0.06 & 0.03 & -0.08 & -0.24 & -1.32 & -1.27 \\
\hline
\end{tabular}


Appendix Table 3b. Average Exit Rates from Unemployment in Indicated Periods, by Sex and Age, 1994-2014

Percent

\begin{tabular}{ccccccccc}
\hline \multicolumn{8}{c}{ Age group } \\
\hline 27- 31 & 32-36 & 37- 41 & $\mathbf{4 2 - 4 6}$ & $\mathbf{4 7 - 5 1}$ & $\mathbf{5 2 - 5 6}$ & $\mathbf{5 7 - 6 1}$ & $\mathbf{6 2 - 6 6}$ & $\mathbf{6 7 - 7 1}$ \\
\hline \multicolumn{7}{c}{ Women } \\
\hline \multicolumn{8}{c}{ Unemployed => Employed } \\
\hline 27.4 & 26.3 & 27.6 & 25.6 & 27.2 & 26.7 & 24.5 & 22.6 & 25.7 \\
24.8 & 23.9 & 24.3 & 25.0 & 25.2 & 22.0 & 23.6 & 21.5 & 17.3 \\
25.6 & 24.5 & 24.6 & 23.4 & 20.9 & 23.1 & 23.3 & 21.8 & 21.8 \\
16.3 & 15.1 & 15.2 & 14.7 & 14.7 & 14.0 & 13.0 & 11.5 & 12.6 \\
17.8 & 16.7 & 18.3 & 19.0 & 18.2 & 16.6 & 16.4 & 14.7 & 13.8
\end{tabular}

Change:

Period *

1994-2000 to 2011-2014

$\begin{array}{lll}-9.6 & -9.6 & -9 .\end{array}$

2001-2003 to 2008-2011

\begin{tabular}{ll|l}
-8.5 & -8.8 & -9.1 \\
\hline
\end{tabular}

$-9.1$

$-6.7$

$-9.0$

$-10.1$

$-8.0$

$-8.0$

$-11.9$

$-10.3$

$-10.5$

$-8.0$

$-10.7$

$-10.1$

$-4.7$

1994-2000

27.8

2001-2003

23.8

26.4

Unemployed $=>$ NILF

2004-2007

26.

2008-2011

23.6

2011-2014

24.9

25.2

25.

24.9

23.4

24.1

29.4

34.8

43.6

Change:

1994-2000 to 2011-2014

2001-2003 to 2008-2011

$-2$.

$-0.1$

25.4

$21.4 \quad 20.4$

$24.2 \quad 23.2$

23.2

$-2.2$

$-3.8$
$-1.9$

$-2.5$

20.6

19.6

21.3

23.5

23.1

33.5

31.2

39.1

20.4

19.1

19.4

22.4

$-0.2$

\section{Men}

Unemployed => Employed

$\begin{array}{llllllllll}1994-2000 & 34.8 & 33.2 & 30.8 & 31.0 & 28.4 & 27.8 & 26.2 & 20.2 & 21.8 \\ 2001-2003 & 30.1 & 30.6 & 27.6 & 27.8 & 25.3 & 22.7 & 21.7 & 20.6 & 20.3 \\ 2004-2007 & 31.3 & 32.1 & 30.6 & 28.2 & 28.5 & 25.2 & 23.7 & 22.1 & 20.0 \\ 2008-2011 & 22.7 & 23.1 & 21.9 & 20.6 & 19.5 & 18.5 & 17.0 & 14.6 & 14.1 \\ 2011-2014 & 22.1 & 23.0 & 21.7 & 20.6 & 20.4 & 18.6 & 17.4 & 15.2 & 14.7\end{array}$

Change:

1994-2000 to 2011-2014

2001-2003 to 2008-2011

$-12$

$-7.3$

$\begin{array}{lll}2.8 & -10.2 & -9 \\ -7.3 & -7.5 & -5.7\end{array}$

$\begin{array}{lll}-7.3 & -7.5 & -5.7\end{array}$

$-9.2-10.4$

$-5.7$

\begin{abstract}
$-10.4$
\end{abstract} $-7.1$

$$
-7.9
$$

$-5.8$
$-9.1$

$-4.2$
$-8.8$

$-4.7$

$-4.9$

$-6.0$
$-7.1$ $-6.3$

$\begin{array}{lrrrrrrrrr}\text { 1994-2000 } & 15.1 & 15.3 & 15.1 & 14.9 & 14.3 & 17.2 & 21.5 & 37.0 & 40.5 \\ 2001-2003 & 14.4 & 12.8 & 12.5 & 13.4 & 13.5 & 15.0 & 17.1 & 29.6 & 41.3 \\ 2004-2007 & 16.3 & 15.0 & 13.8 & 15.5 & 16.0 & 17.4 & 20.3 & 31.8 & 38.7 \\ 2008-2011 & 13.5 & 13.8 & 11.9 & 12.2 & 11.9 & 13.1 & 15.2 & 24.9 & 29.4 \\ \begin{array}{l}2011-2014 \\ \text { ge: }\end{array} & 15.8 & 15.4 & 14.7 & 14.7 & 15.9 & 16.2 & 17.7 & 26.6 & 34.8 \\ -2000 \text { to 2011-2014 } & & & & & & & & & \\ -2003 \text { to 2008-2011 } & -0.8 & 0.1 & -0.5 & -0.2 & 1.7 & -1.0 & -3.8 & -10.5 & -5.8 \\ \end{array}$


Appendix Table 3c. Average Exit Rates from Out-of-the-Labor-Force Status in Indicated Periods, by Sex and Age, 1994-2014

Percent

\begin{tabular}{|c|c|c|c|c|c|c|c|c|c|}
\hline \multirow[b]{4}{*}{ Period* } & \multicolumn{9}{|c|}{ Age group } \\
\hline & $27-31$ & $32-36$ & $37-41$ & $42-46$ & 47- 51 & $52-56$ & 57- 61 & 62-66 & 67- 71 \\
\hline & \multicolumn{9}{|c|}{ Women } \\
\hline & \multicolumn{9}{|c|}{ NILF => Employed } \\
\hline $1994-2000$ & 7.3 & 6.6 & 6.8 & 6.5 & 5.7 & 4.3 & 3.1 & 2.0 & 1.2 \\
\hline 2001-2003 & 7.7 & 7.0 & 7.0 & 6.8 & 6.0 & 4.9 & 3.3 & 2.2 & 1.3 \\
\hline 2004-2007 & 7.5 & 6.7 & 6.5 & 6.7 & 5.8 & 4.7 & 3.6 & 2.2 & 1.5 \\
\hline 2008-2011 & 5.7 & 5.4 & 5.3 & 5.4 & 5.1 & 4.4 & 3.3 & 2.3 & 1.5 \\
\hline 2011-2014 & 6.1 & 5.6 & 5.5 & 5.2 & 4.7 & 4.3 & 3.1 & 2.3 & 1.5 \\
\hline
\end{tabular}

Change:

1994-2000 to 2011-2014

$\begin{array}{lllllllll}-1.2 & -1.0 & -1.3 & -1.3 & -1.0 & 0.0 & 0.0 & 0.3 & 0.3\end{array}$

2001-2003 to 2008-2011

$-2.0-1.6 \quad-1.7$

$-1.4-0.9$

$-0.6$

$\begin{array}{lll}0.0 & 0.0 & 0.2\end{array}$

1994-2000

2001-2003

2004-2007

2008-2011

2011-2014

Change:

1994-2000 to 2011-2014

2001-2003 to 2008-2011

$\begin{array}{llllll}4.4 & 3.7 & 3.4 & 3.0 & 2.4 & 1.5\end{array}$

4.1

3.7

5.8

5.1
3.2

3.1

4.7

3.0

2.9

4.7

4.2
2.9

3.1

4.3

3.7
2.4

2.5

3.6

3.2
1.5

1.5

1.7

2.8

2.6
0.7

1.4
0.8

1.2

1.1

1.2

$\begin{array}{ll}0.9 & 0.4\end{array}$

$1.1 \quad 0.5$

$1.2 \quad 0.6$

$2.1 \quad 0.9$

$1.7 \quad 0.9$
0.2

\section{Men}

NILF => Employed

$\begin{array}{rrrrrrrrrr}1994-2000 & 14.4 & 12.0 & 9.8 & 8.0 & 6.3 & 5.3 & 3.9 & 3.0 & 2.1 \\ 2001-2003 & 14.6 & 12.2 & 10.9 & 7.8 & 6.9 & 5.5 & 4.2 & 2.9 & 2.2 \\ 2004-2007 & 14.3 & 12.5 & 10.3 & 8.2 & 6.9 & 5.1 & 4.0 & 3.1 & 2.3 \\ 2008-2011 & 10.8 & 10.5 & 9.0 & 7.0 & 5.8 & 4.7 & 3.6 & 2.7 & 2.3 \\ 2011-2014 & 10.5 & 9.4 & 8.5 & 7.4 & 5.7 & 4.4 & 3.8 & 2.5 & 2.2\end{array}$

Change:

1994-2000 to 2011-2014

2001-2003 to 2008-2011

\section{$-3.9$}

$-3.9$

\begin{tabular}{lrrrrrrrrr}
$1994-2000$ & 8.6 & 7.4 & 5.8 & 4.8 & 3.6 & 2.6 & 1.5 & 0.8 & 0.4 \\
$2001-2003$ & 9.1 & 8.1 & 6.6 & 5.2 & 3.8 & 2.8 & 1.8 & 0.8 & 0.4 \\
$2004-2007$ & 8.3 & 6.7 & 5.5 & 4.7 & 3.7 & 2.5 & 1.5 & 0.7 & 0.5 \\
$2008-2011$ & 11.1 & 10.7 & 8.9 & 6.7 & 5.4 & 3.8 & 2.4 & 1.4 & 0.8 \\
$2011-2014$ & 10.3 & 8.1 & 7.8 & 5.9 & 4.7 & 3.6 & 2.5 & 1.4 & 0.8 \\
ge: & & & & & & & & & \\
2000 to $2011-2014$ & 1.6 & 0.7 & 2.0 & 1.0 & 1.2 & 0.9 & 1.0 & 0.6 & 0.4 \\
2003 to $2008-2011$ & 2.0 & 2.6 & 2.3 & 1.5 & 1.6 & 1.0 & 0.6 & 0.6 & 0.3 \\
\hline
\end{tabular}

9.1

8.1

6.7

$11.1 \quad 10.7$

10.3

8.1

2011-2014

Change:

\begin{tabular}{lllllllll}
1.6 & 0.7 & 2.0 & 1.0 & 1.2 & 0.9 & 1.0 & 0.6 & 0.4 \\
2.0 & 2.6 & 2.3 & 1.5 & 1.6 & 1.0 & 0.6 & 0.6 & 0.3 \\
\hline
\end{tabular}


Notes to Appendix Tables 3a - 3c: Period intervals are selected to correspond with late recovery periods, on the one hand, and recessions plus the first 24 months of the following recovery, on the other. The period designated "19942000” includes Feb. 1994 to Mar. 2001; “2001-2003” includes Apr. 2001-Nov. 2003; “2004-2007” includes Dec. 2003-Dec. 2007; “2008-2011” includes Jan. 2008-Jun. 2011; and “2011-2014” includes Jul. 2011-Dec. 2014. See text. Monthly exit rates are calculated as a percent of employed persons, unemployed persons, or persons not in the labor force in the preceding month. For example, the exit rate $\mathrm{E}=>\mathrm{U}$ is calculated as the ratio of persons exiting from $\mathrm{E}=>\mathrm{U}$ to the number of employed in the initial month. Calculations are performed using longitudinal CPS weights. The reported average rates over multi-month periods are the arithmetic averages of monthly exit rates in the indicated periods.

Source: Author's calculations of matched monthly CPS interview records as described in text. 
Figure 1. Change in Labor Force Participation Rate, by Sex and Age, 2007-2014

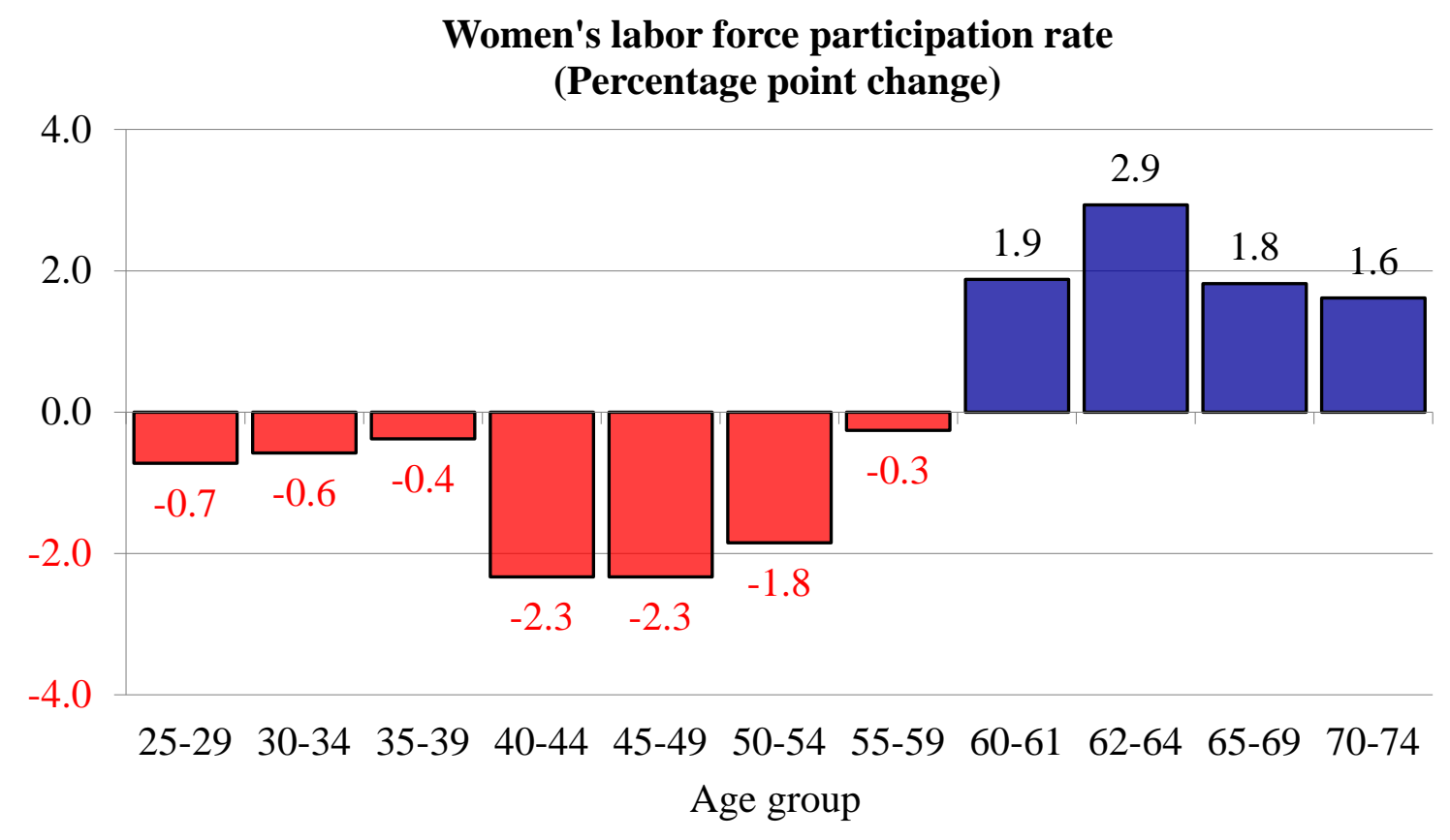

\section{Men's labor force participation rate}

(Percentage point change)

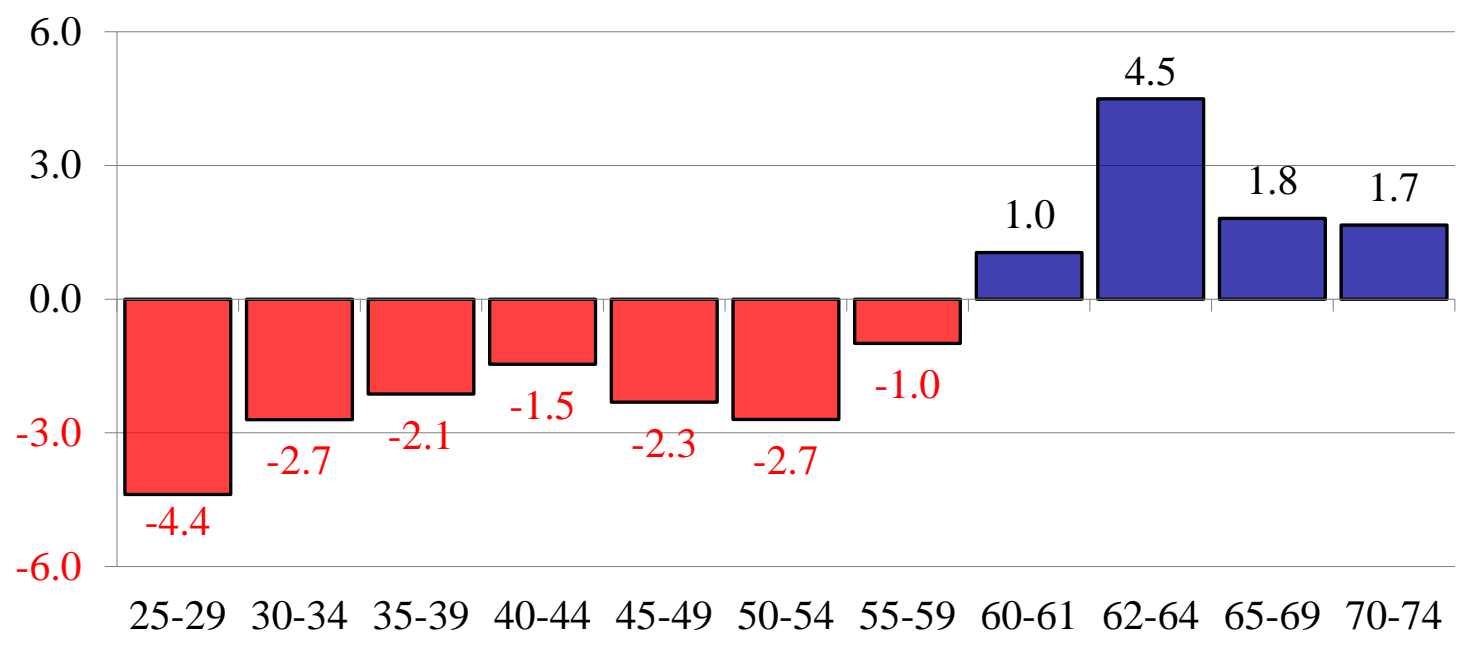

Age group

Source: Author's calculations of U.S. BLS data. 
Figure 2. Change in Employment-Population Ratio, by Sex and Age, 2007-2014

Women's employment-population ratio (Percentage point change)

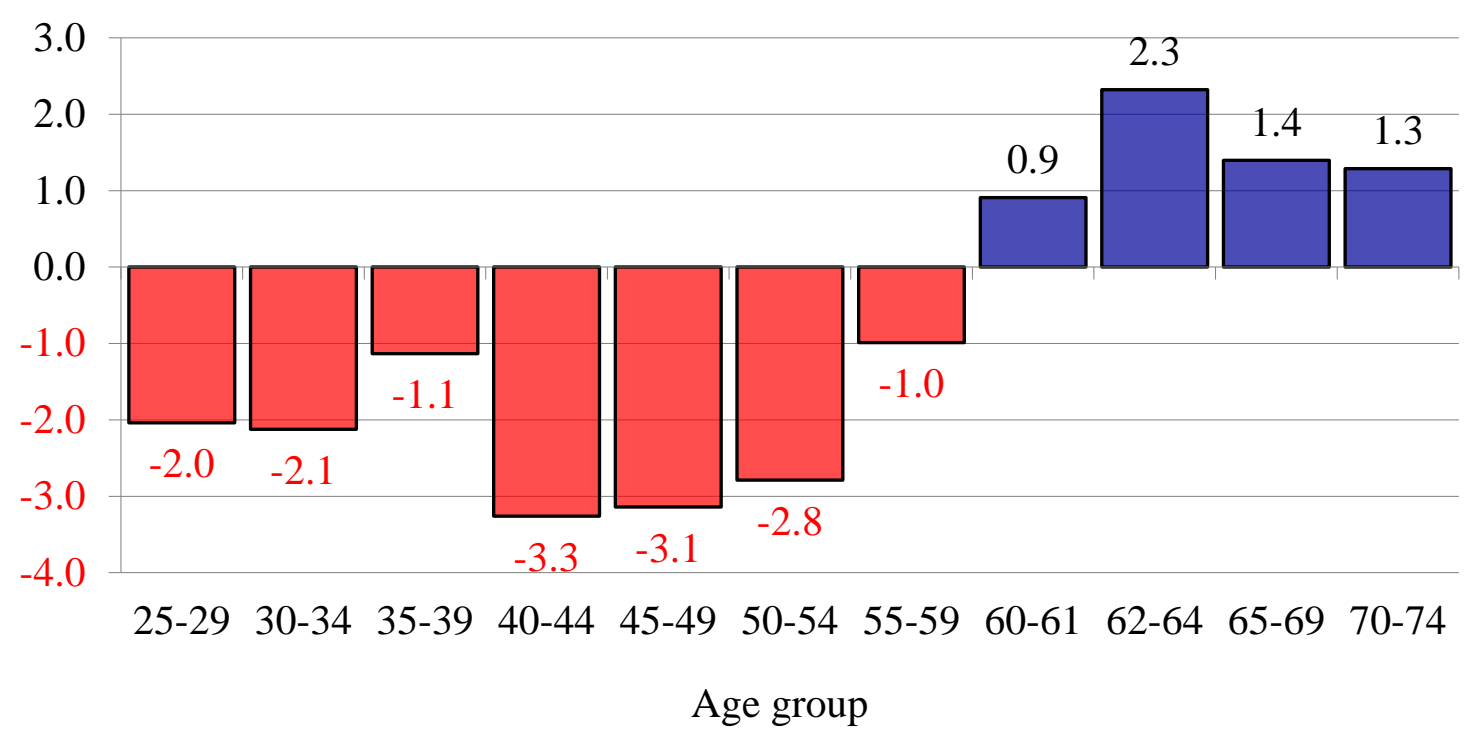

Men's employment-population ratio

(Percentage point change)

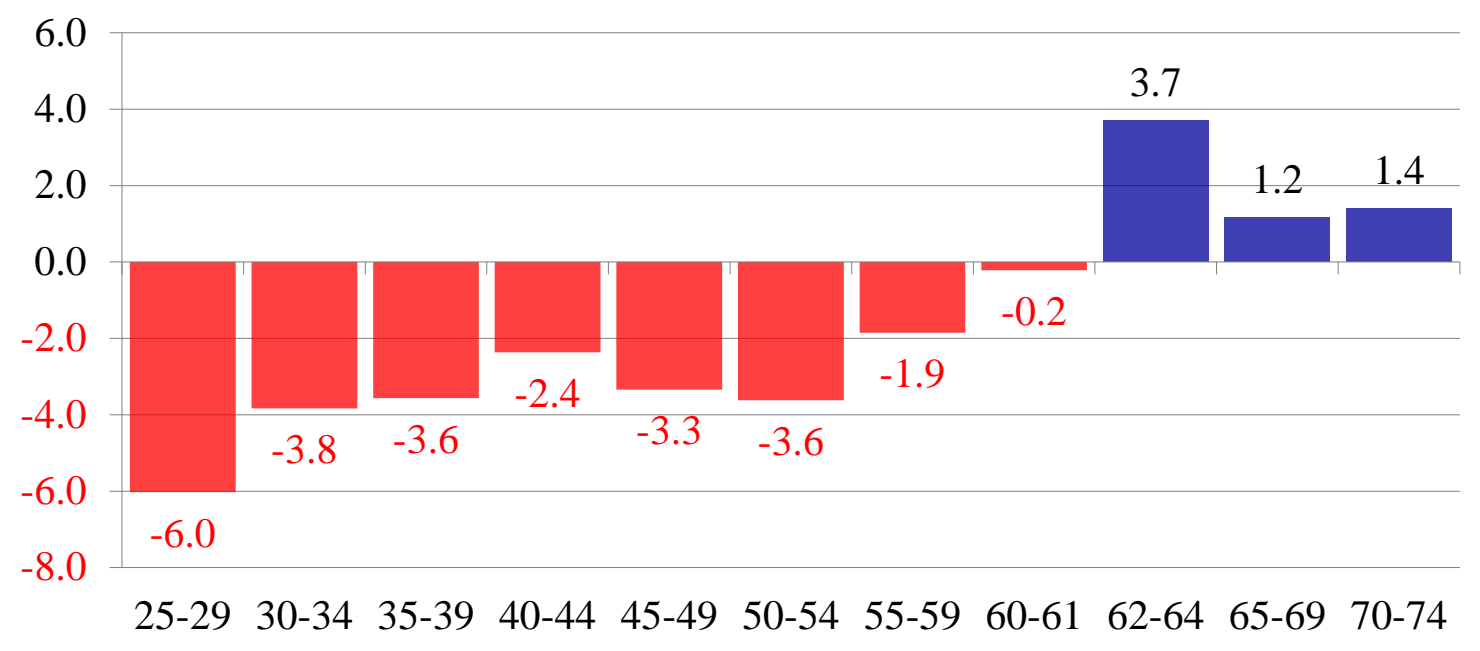

Age group

Source: Author's calculations of U.S. BLS data. 
Figure 3. Labor Force Transition Rates, Both Sexes, 1994-2015, 12-Month Centered Moving Average
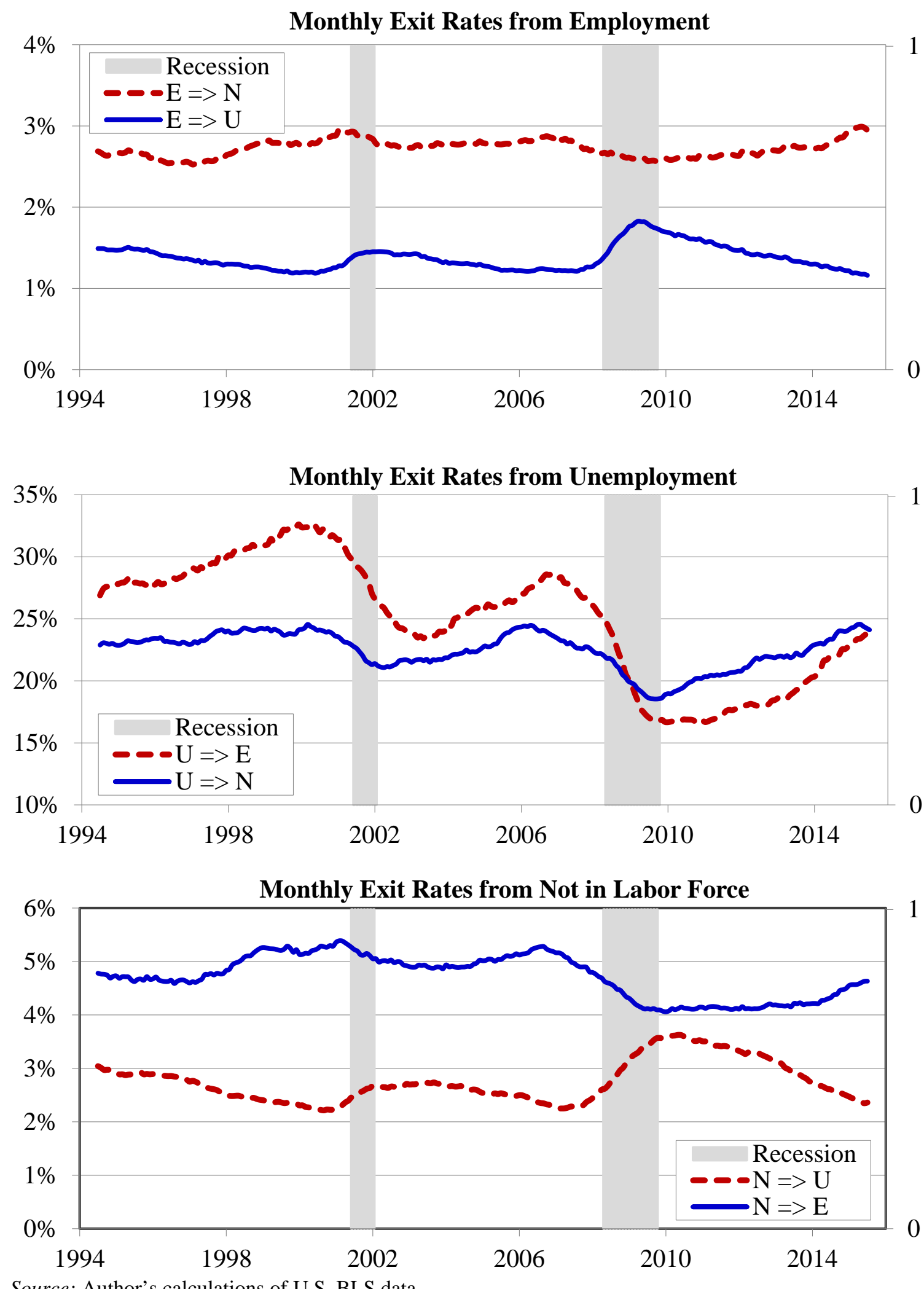

Source: Author's calculations of U.S. BLS data. 
Figure 4. Monthly Transition Rate from Employment to Unemployment among Women, by Age Group, 1994-2014, 12-Month Centered Moving Average
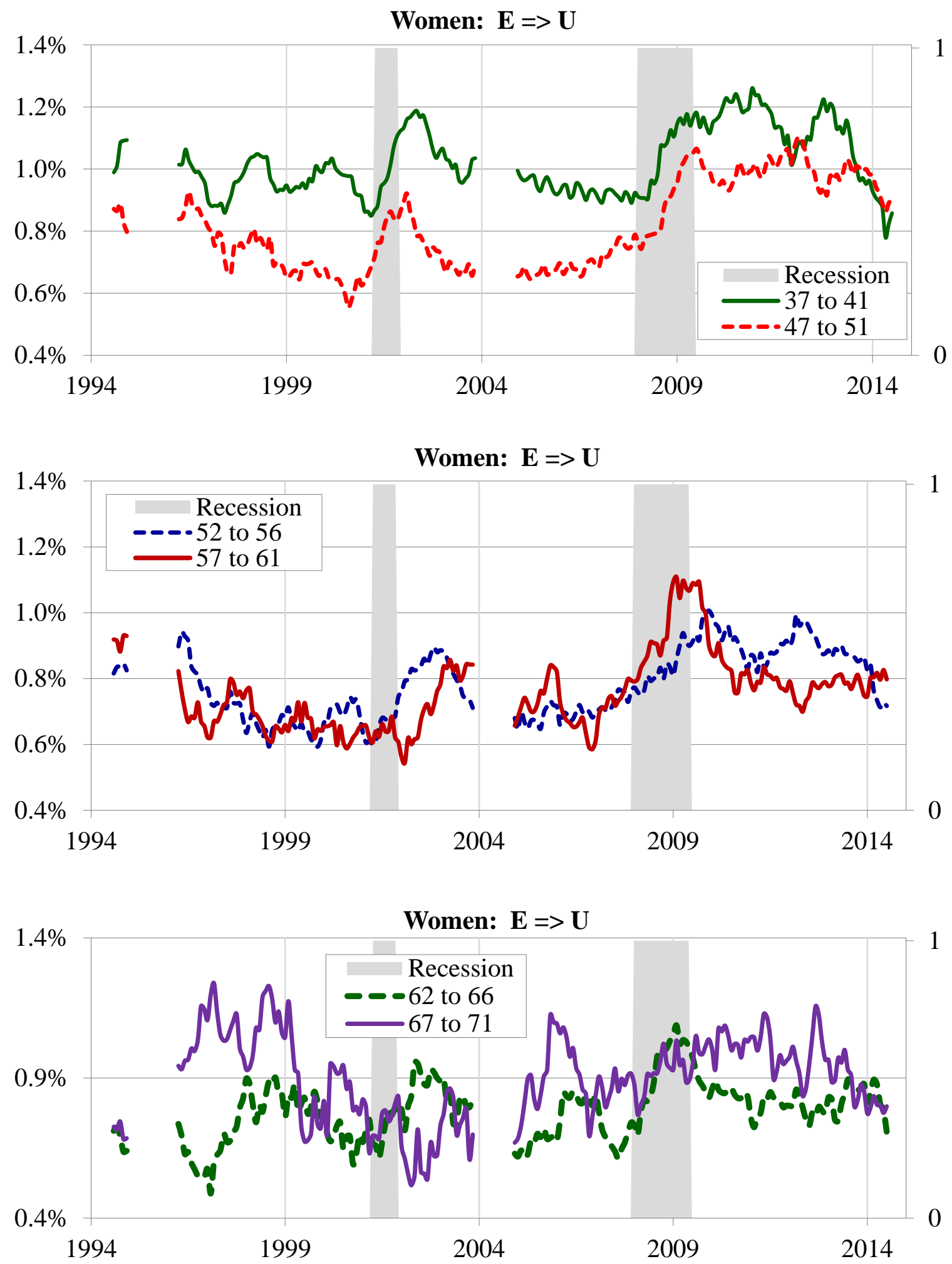

Source: Author's calculations of matched CPS interview records as described in text. 
Figure 5. Monthly Transition Rate from Employment to Unemployment among Men, by Age Group, 1994-2014
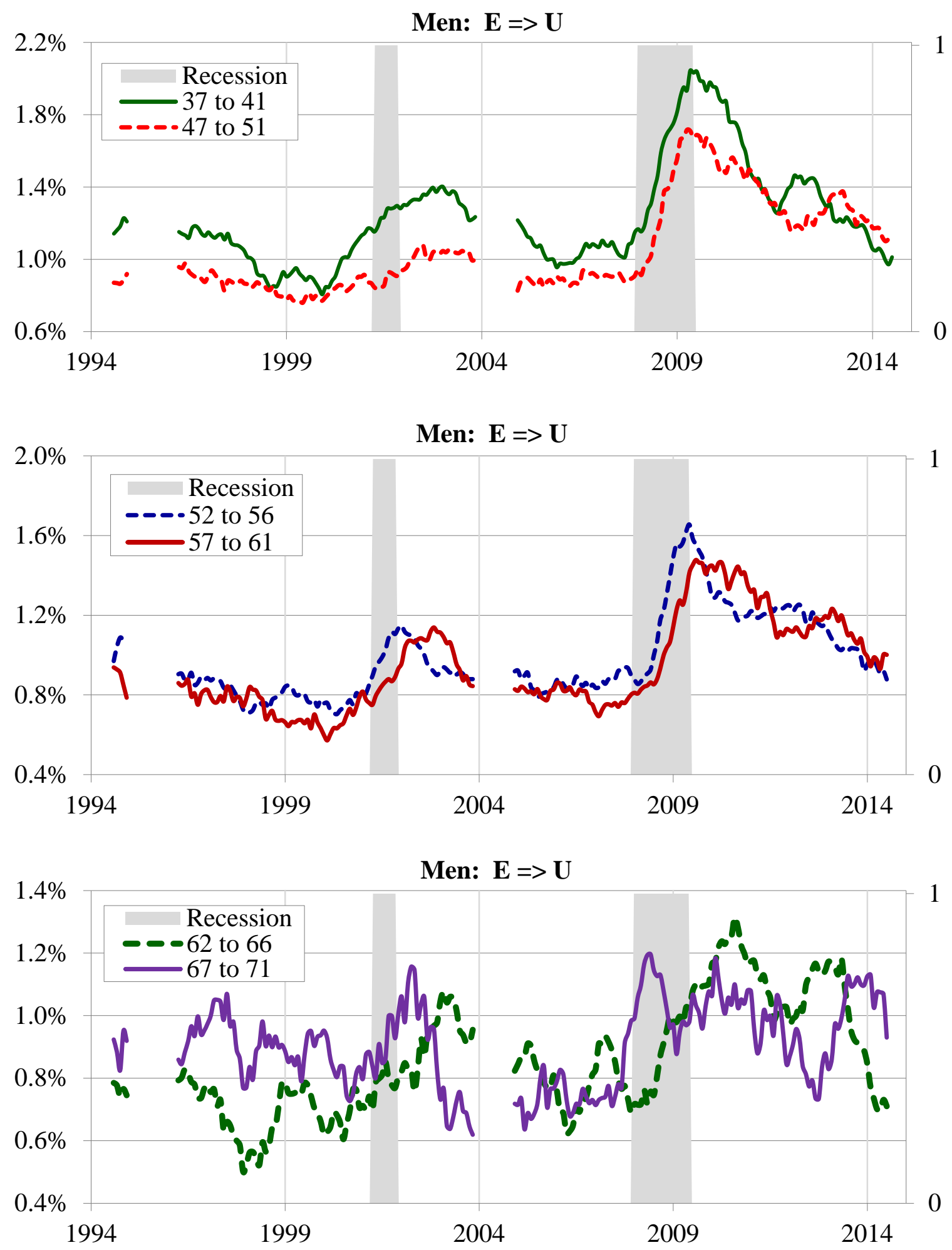

Source: Author's calculations of matched CPS interview records as described in text. 
Figure 6. Monthly Transition Rate from Employment to Nonparticipation, by Sex and Age Group, 1994-2014
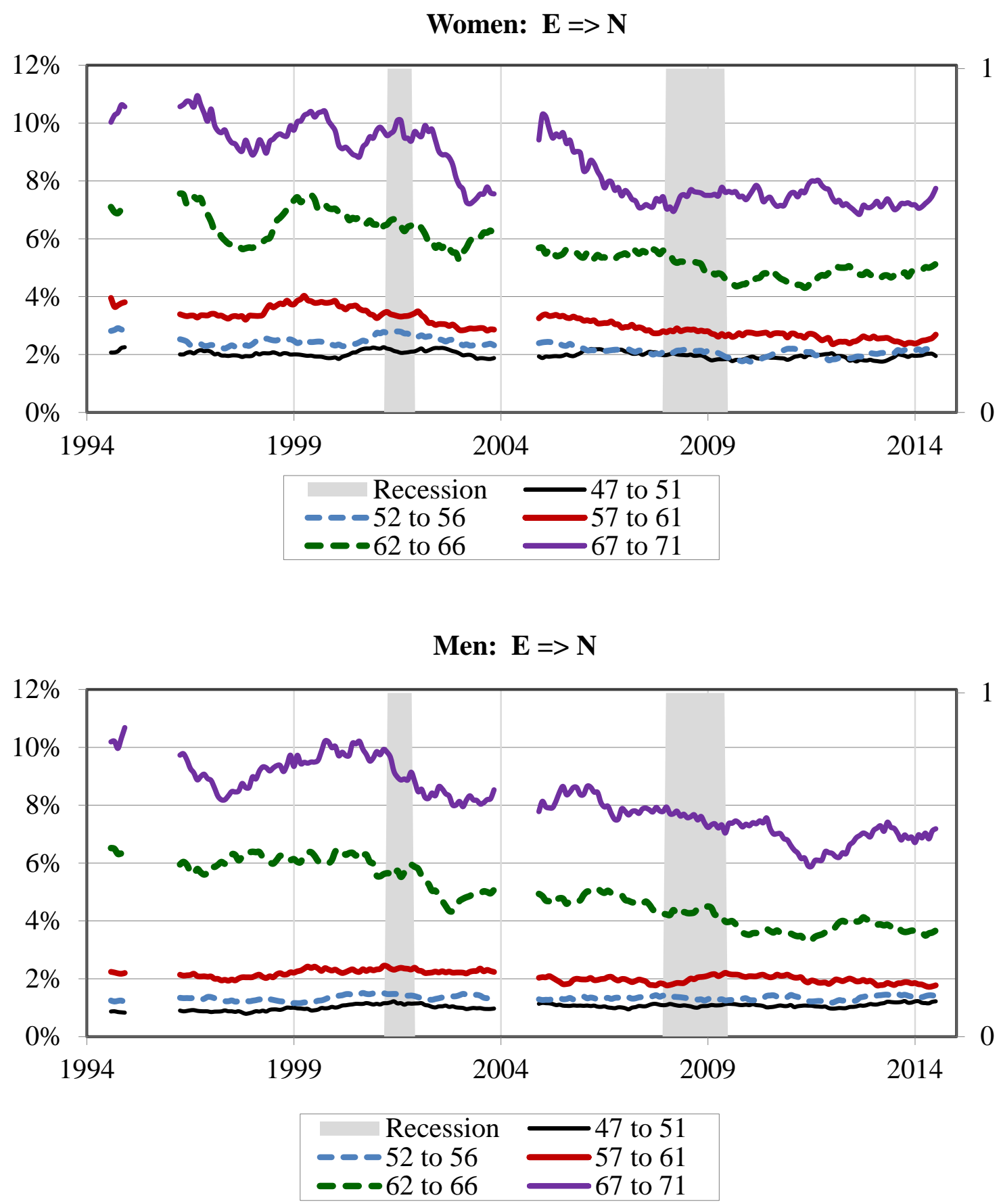

Source: Author's calculations of matched CPS interview records as described in text. 
Figure 7. Monthly Transition Rate from Employment to Nonparticipation among Women, by Age Group, 1994-2014

\section{$\mathrm{E}=>\mathrm{N}$ exit rate by age group}

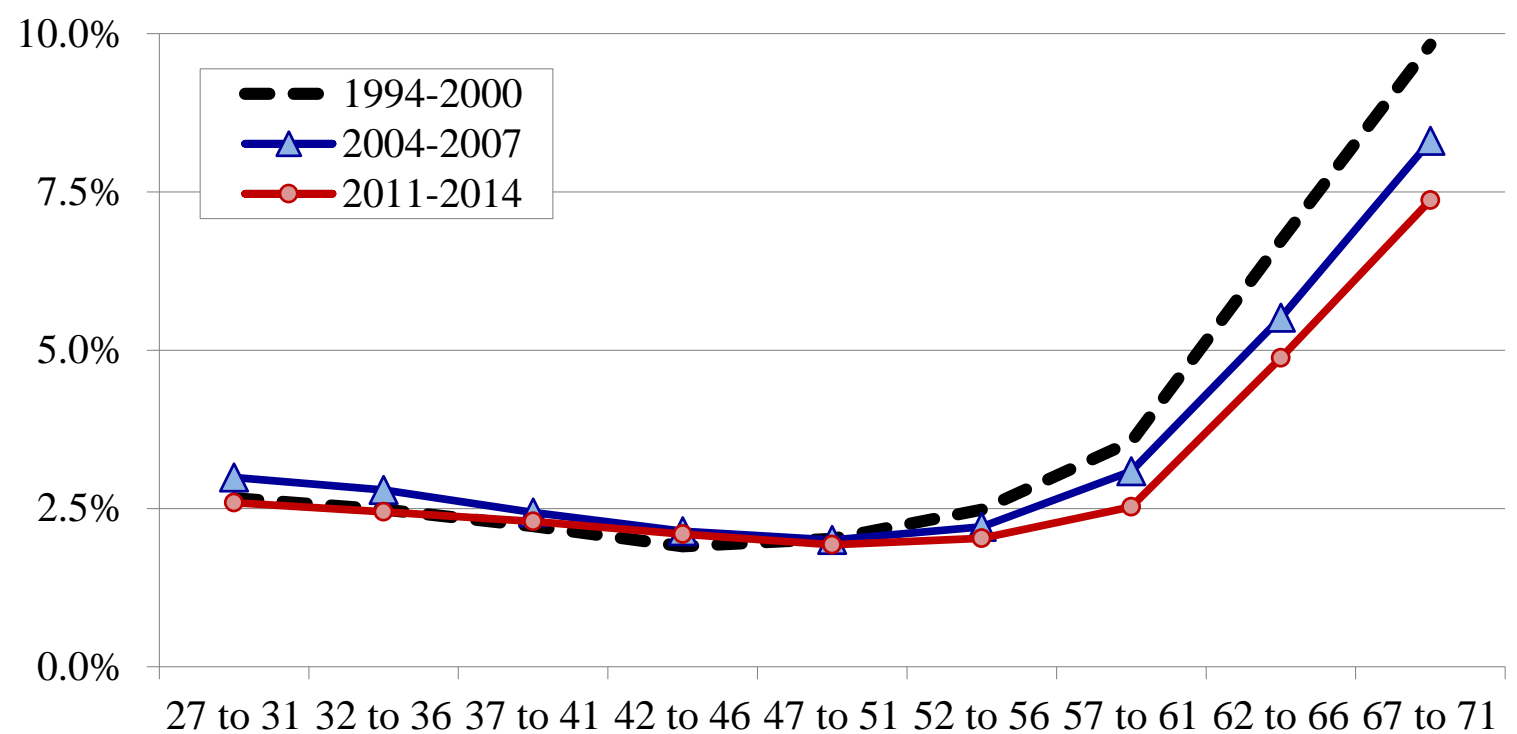

Change in $\mathrm{E}=>\mathrm{N}$ exit rate by age group

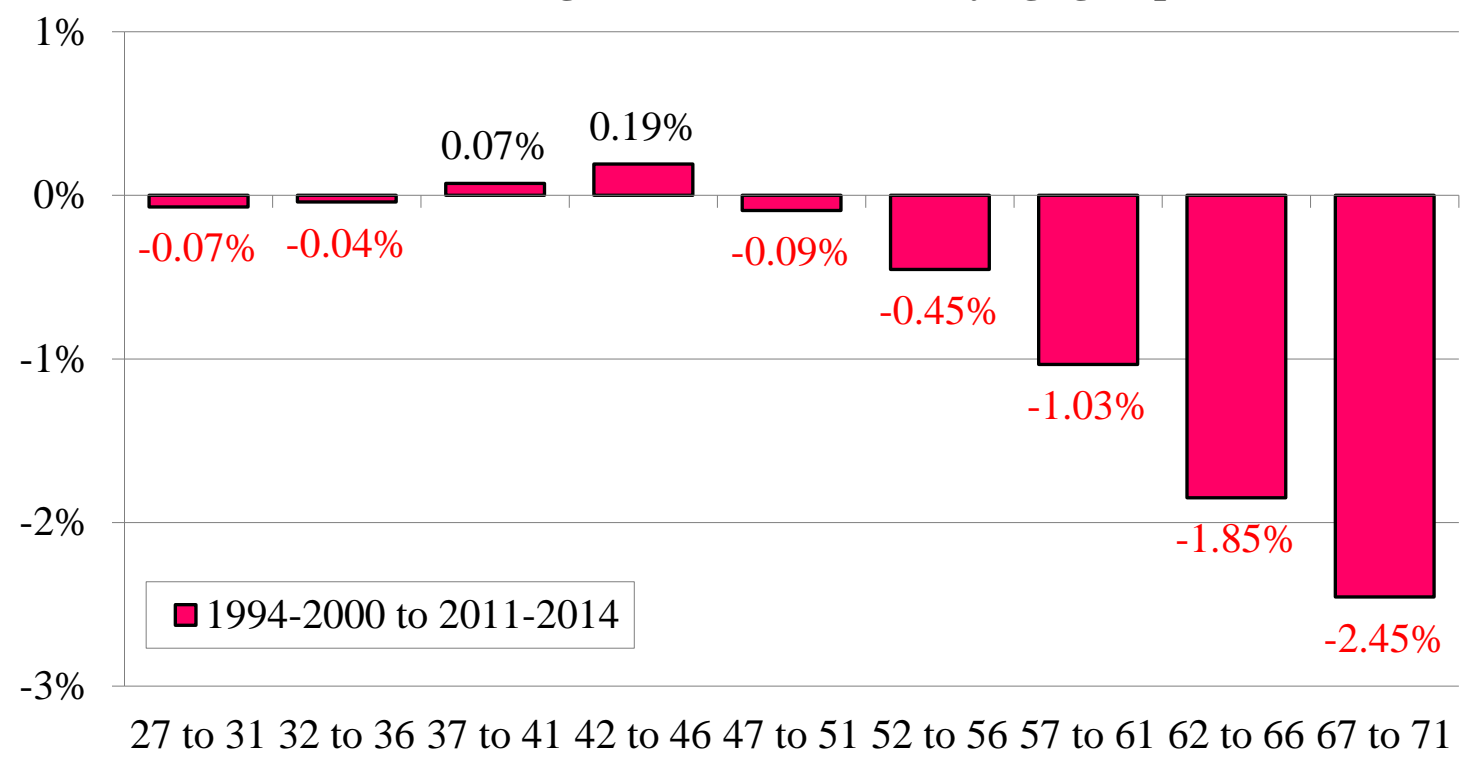

Source: Author's calculations of matched CPS interview records as described in text. Definitions of the indicated periods are given in the notes to Appendix Table 1. 
Figure 8. Monthly Transition Rate from Employment to Nonparticipation among Men, by Age Group, 1994-2014

\section{$\mathrm{E}=>\mathrm{N}$ exit rate by age group}

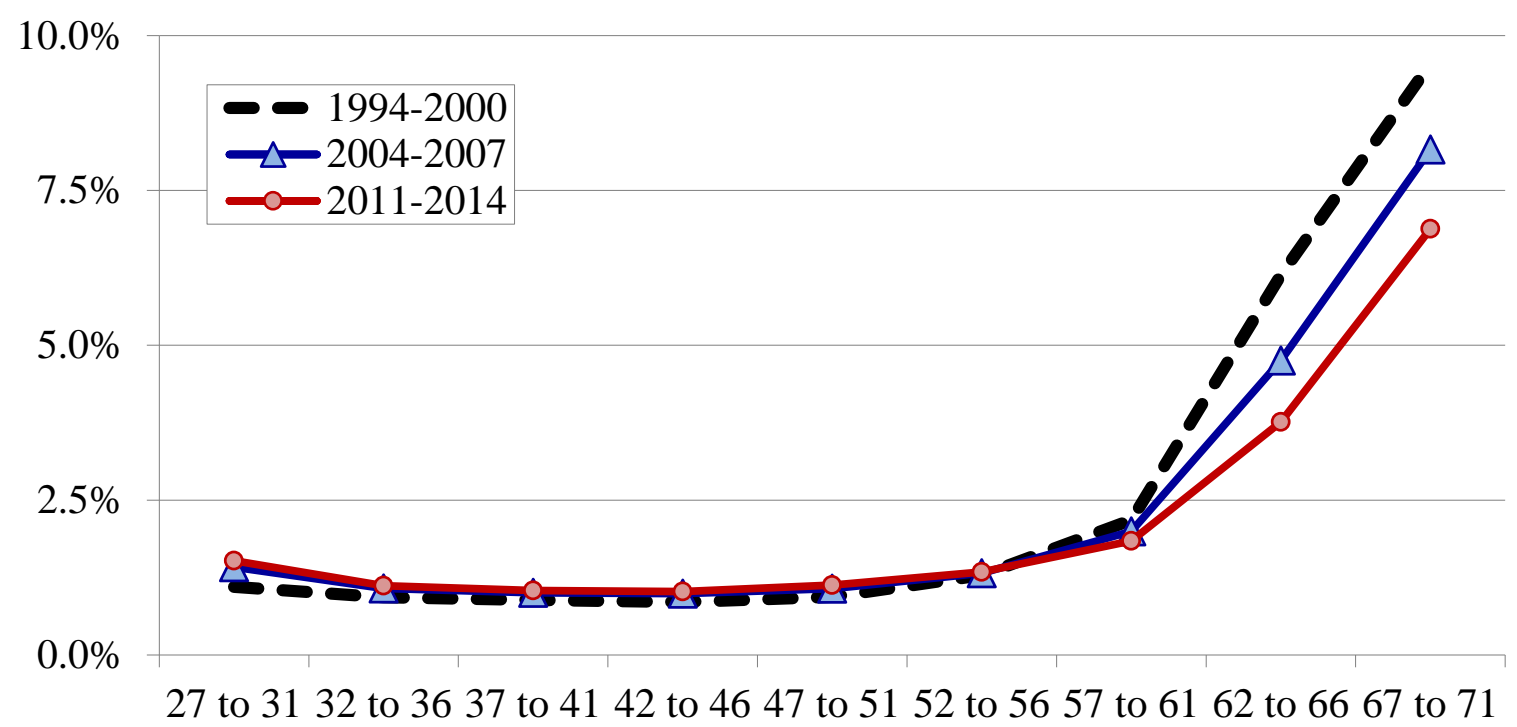

Change in $E=>N$ exit rate by age group

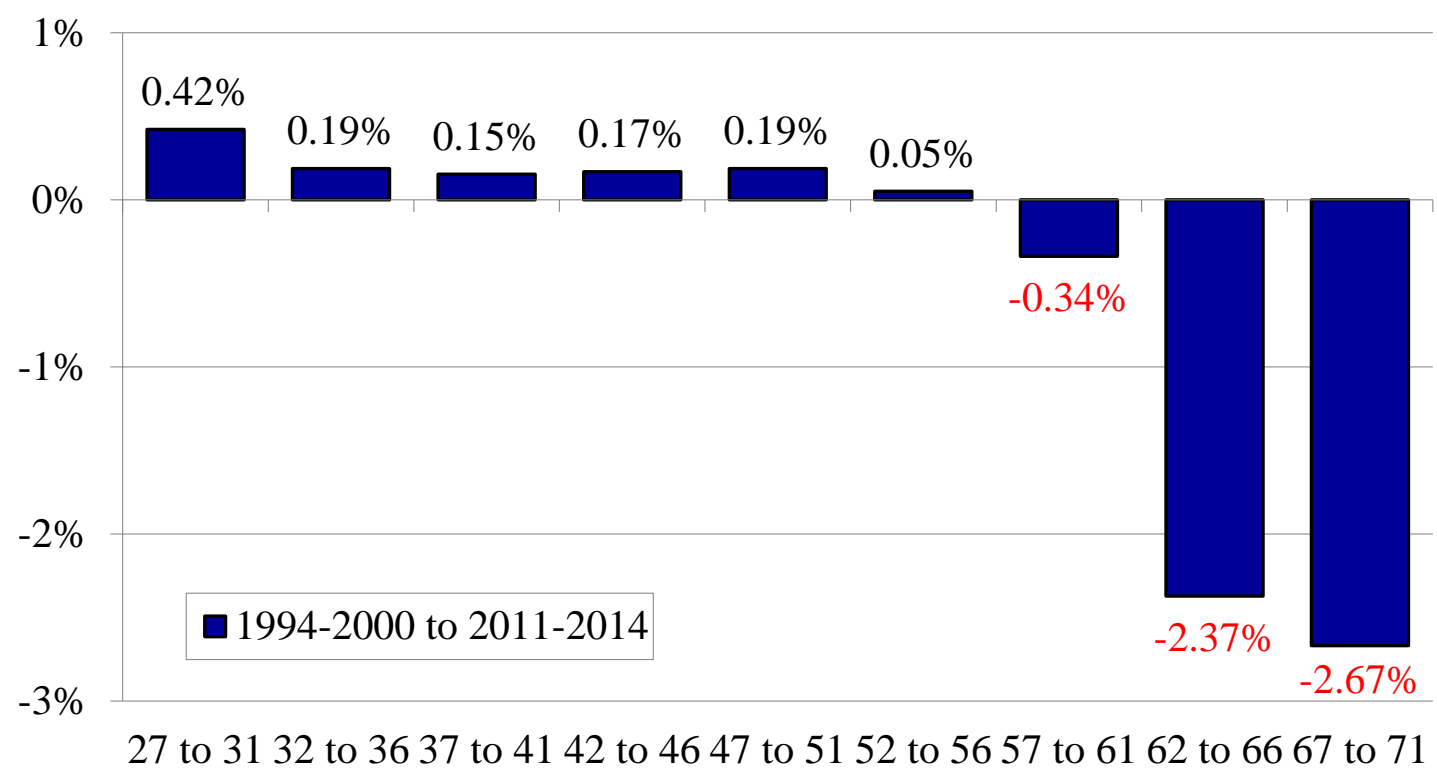

Source: Author's calculations of matched CPS interview records as described in text. Definitions of the indicated periods are given in the notes to Appendix Table 1. 
Figure 9. Monthly Transition Rate from Employment to Nonparticipation among Men, by Age Group, 2001-2011

$$
E=>N \text { exit rate by age group }
$$

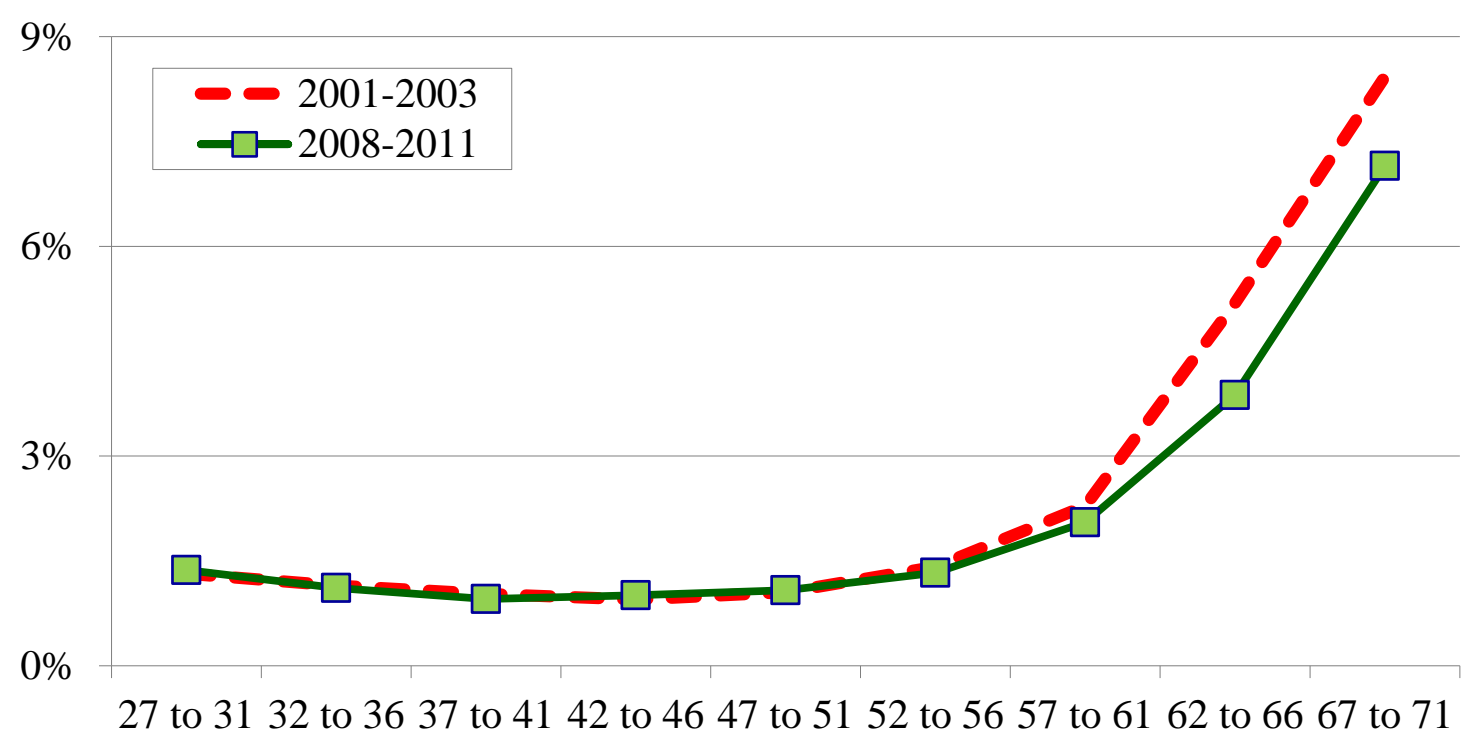

Change in $E=>N$ exit rate by age group

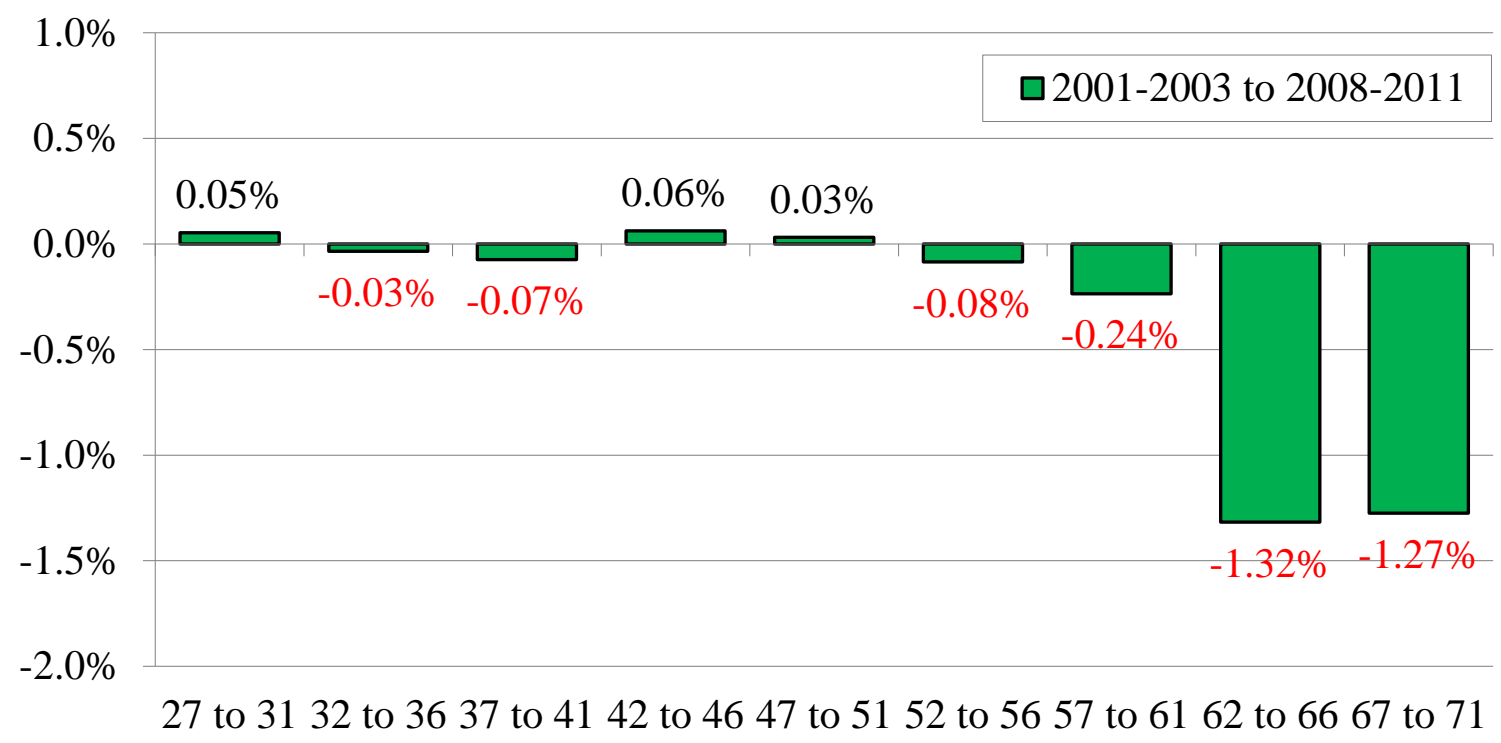

Source: Author's calculations of matched CPS interview records as described in text. Definitions of the indicated periods are given in the notes to Appendix Table 1. 
Figure 10. Monthly Transition Rate from Employment to Joblessness, by Sex and Age Group, 1994-2014

Change in women's $E=>$ Joblessness exit rate by age group
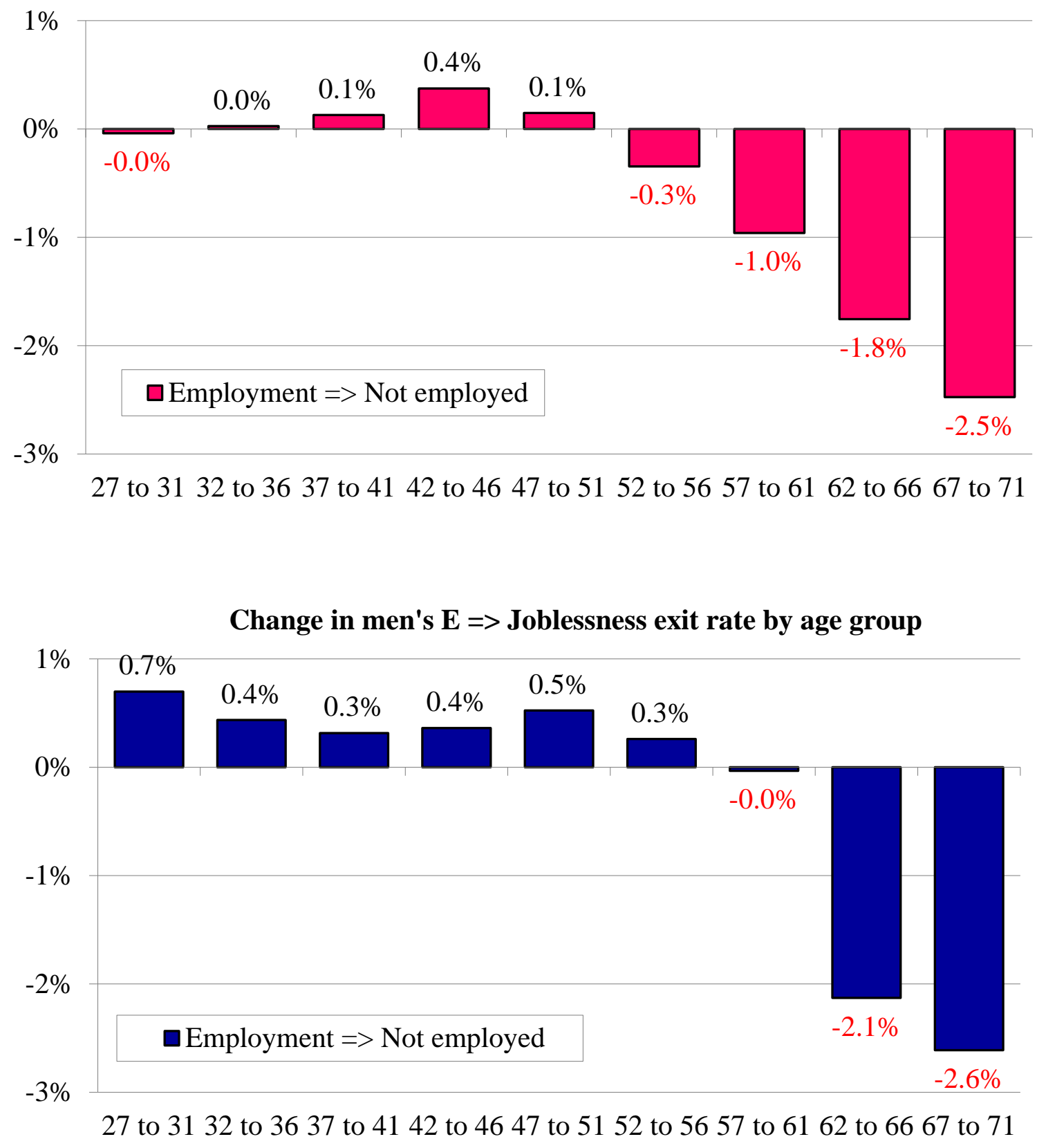

Source: Author's calculations of matched CPS interview records as described in text. Definitions of the indicated periods are given in the notes to Appendix Table 1. 
Figure 11. Monthly Transition Rate from Unemployment to Employment, by Sex and Age Group, 1994-2014

Change in women's $U=>E$ exit rate by age group

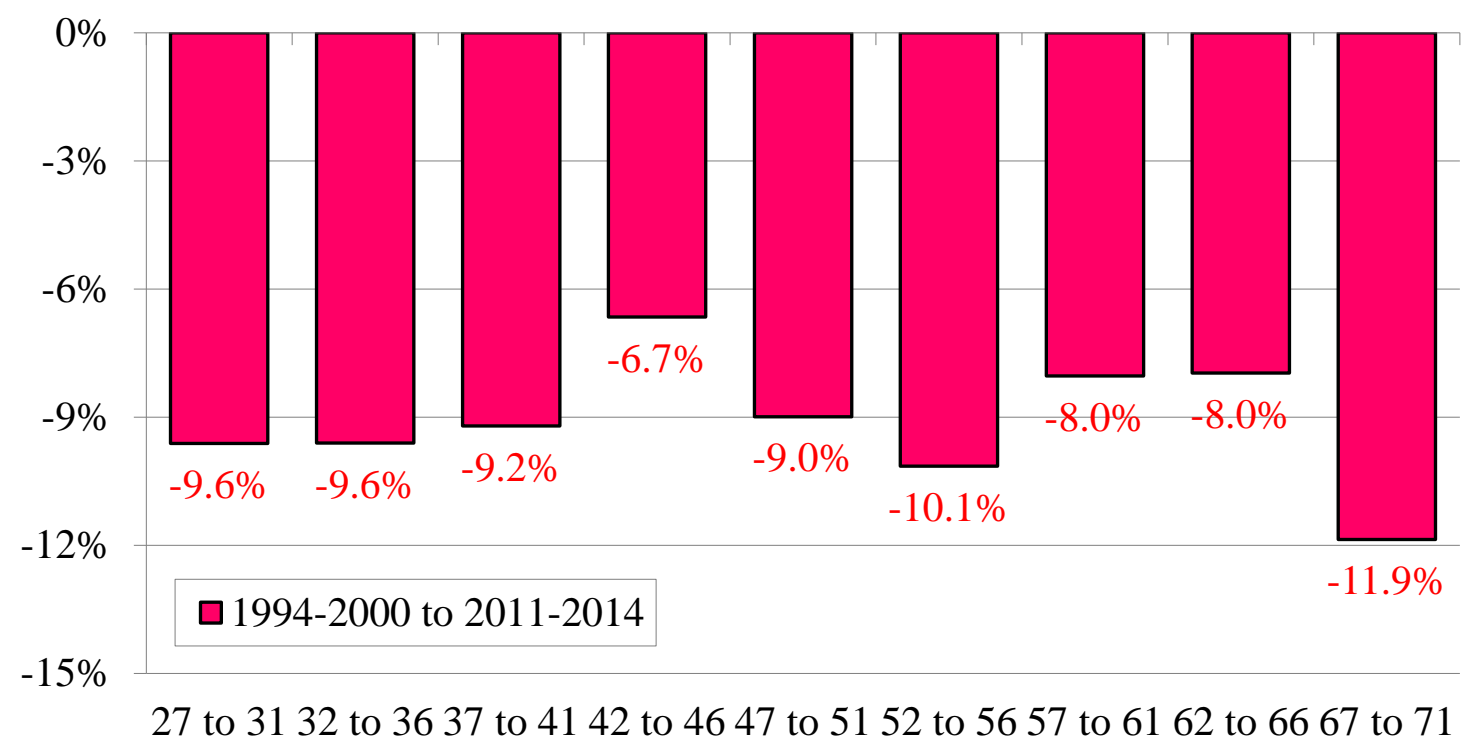

Change in men's $U=>E$ exit rate by age group

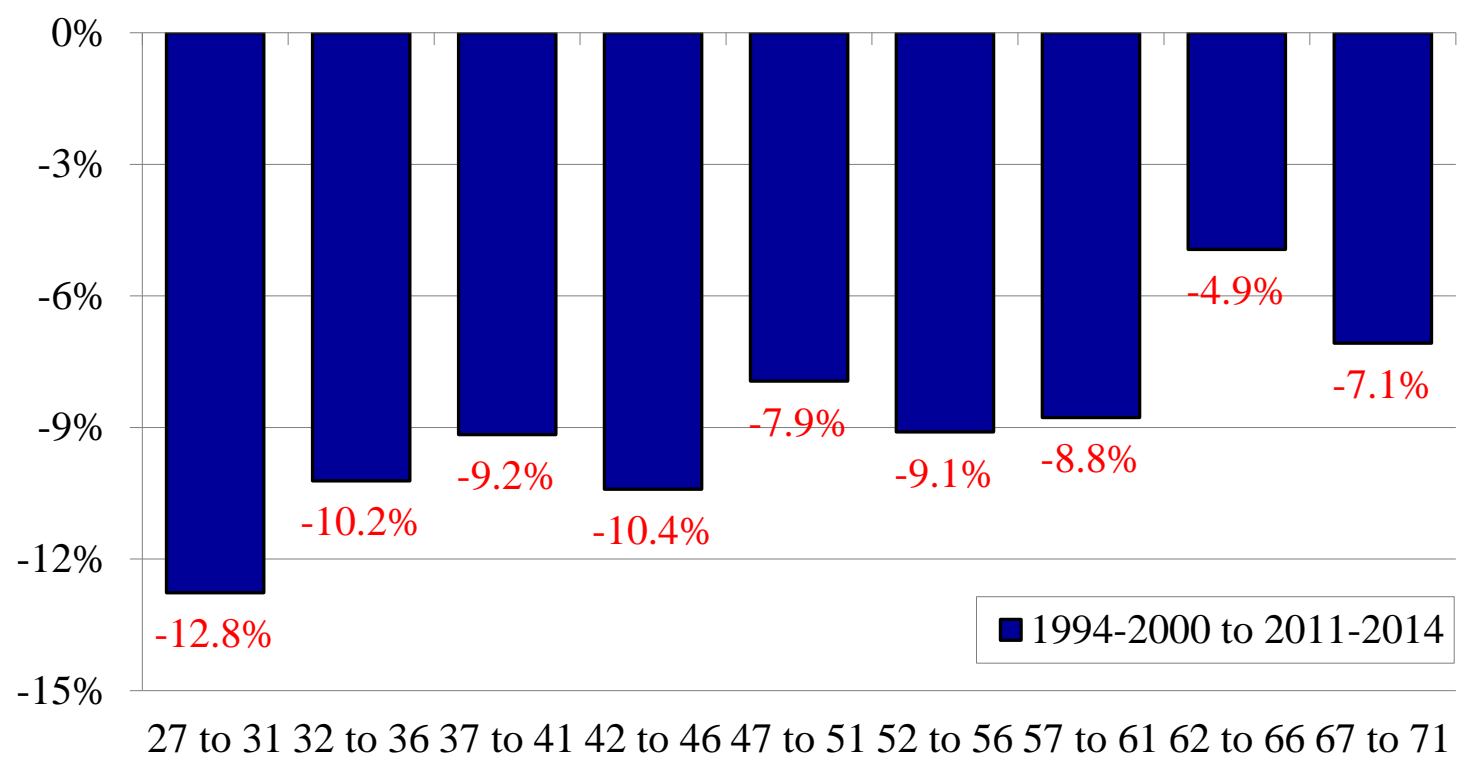

Source: Author's calculations of matched CPS interview records as described in text. Definitions of the indicated periods are given in the notes to Appendix Table 1. 
Figure 12. Monthly Transition Rate from Unemployment to Nonparticipation among Men, by Age Group, 1994-2014

$$
\mathrm{U}=>\mathbf{N} \text { exit rate by age group }
$$

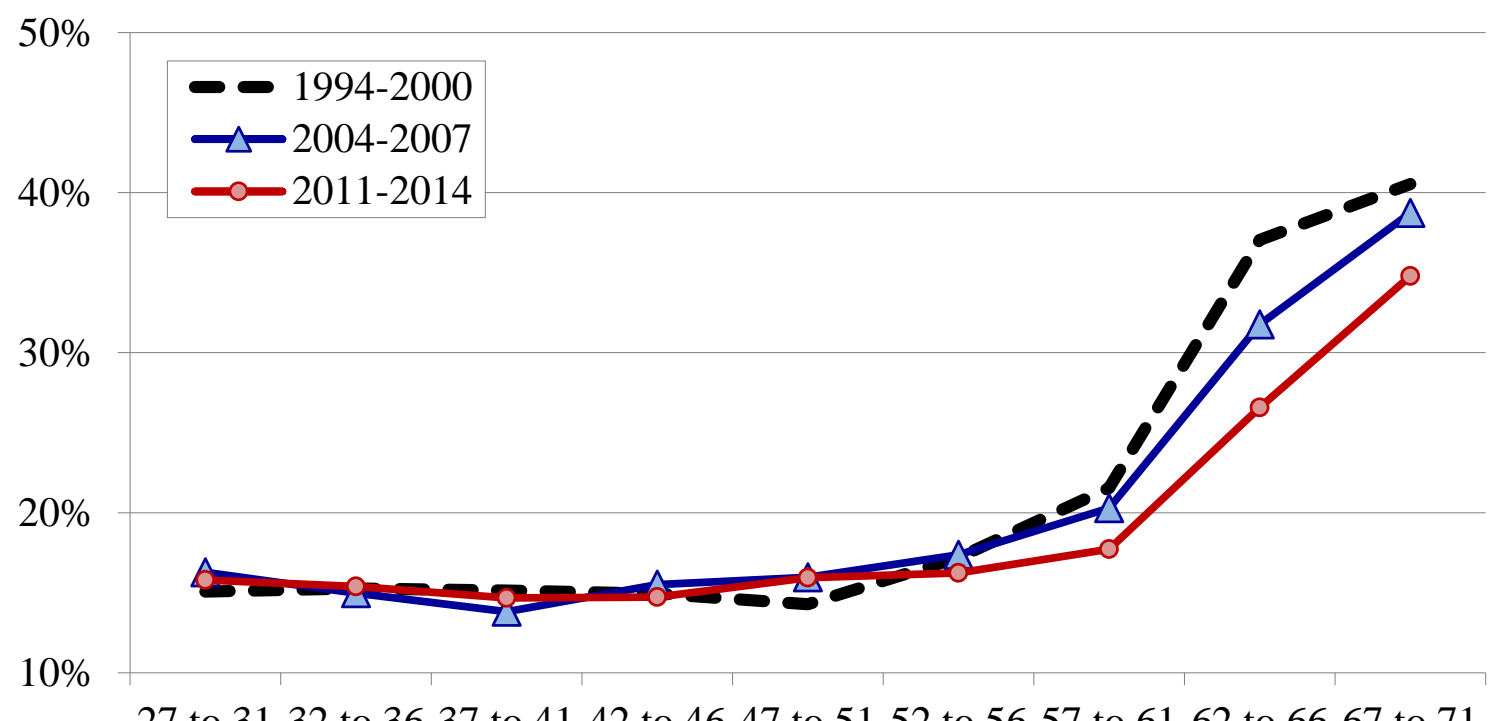

27 to 3132 to 3637 to 4142 to 4647 to 5152 to 5657 to 6162 to 6667 to 71

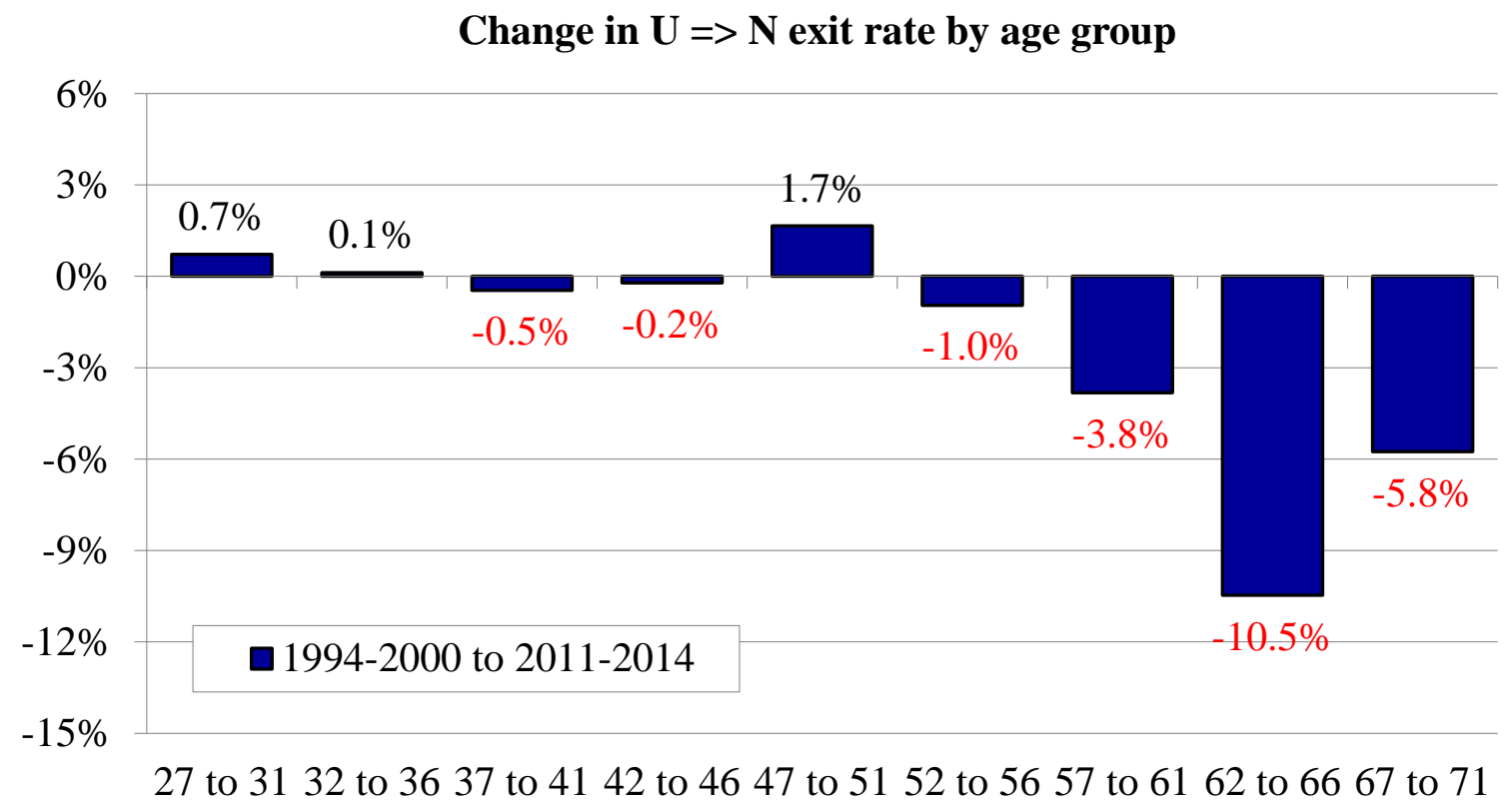

Source: Author's calculations of matched CPS interview records as described in text. Definitions of the indicated periods are given in the notes to Appendix Table 1. 
Figure 13. Monthly Transition Rate from Nonparticipation to Employment among Women, by Age Group, 1994-2014

$$
\mathrm{N}=>\mathrm{E} \text { exit rate by age group }
$$

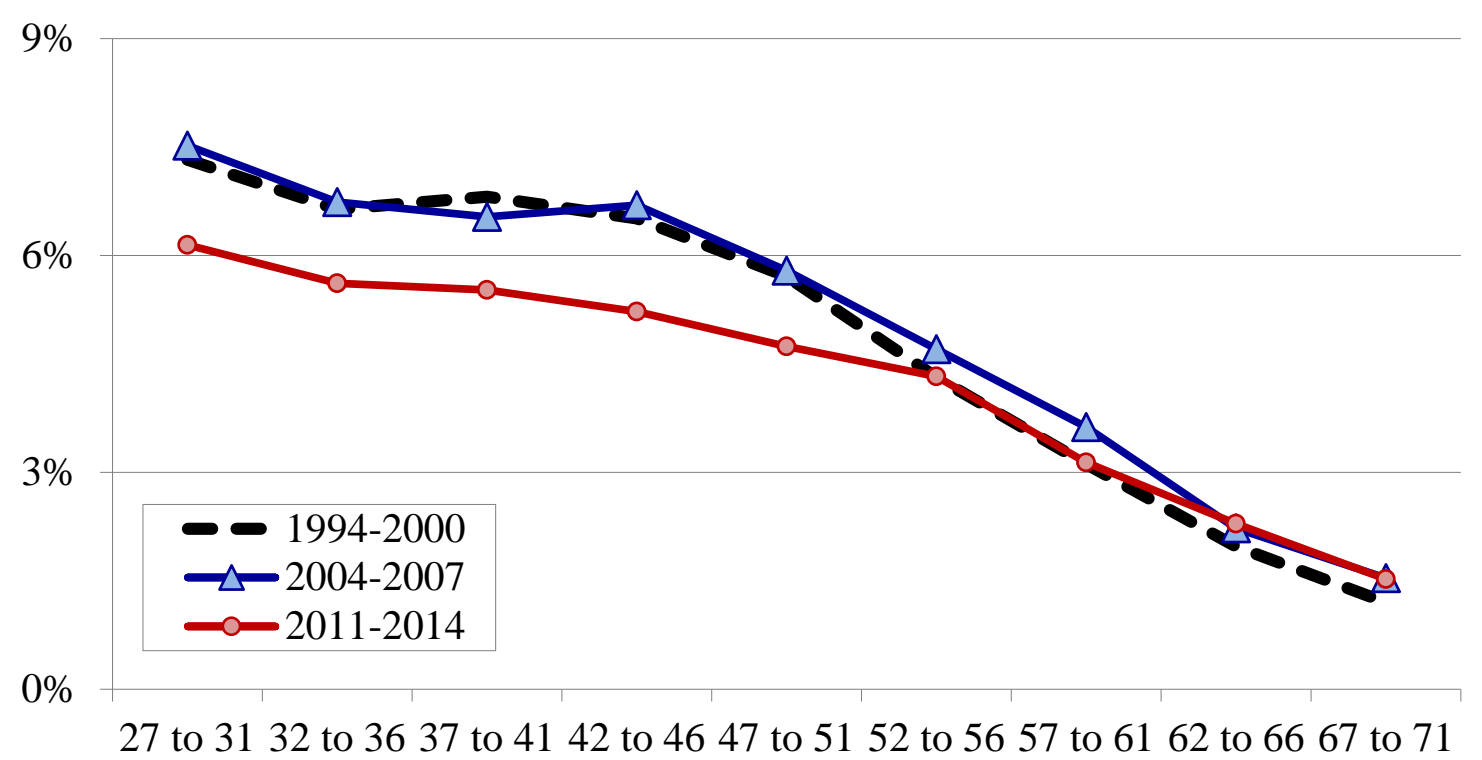

Change in $\mathrm{N}=>\mathrm{E}$ exit rate by age group

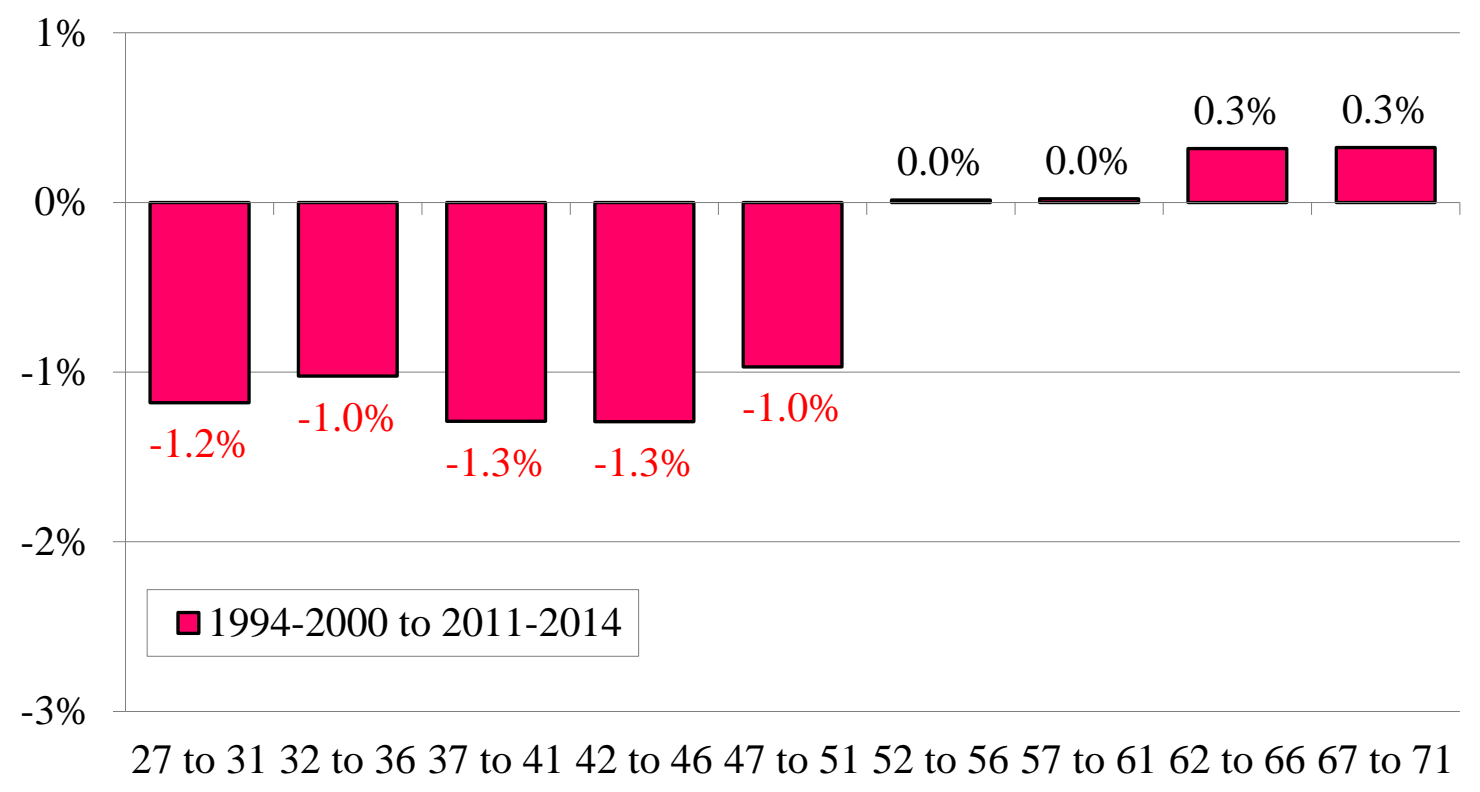

Source: Author's calculations of matched CPS interview records as described in text. Definitions of the indicated periods are given in the notes to Appendix Table 1. 
Figure 14. Changes in Monthly Transition Rate from Nonparticipation to Employment among Men, by Age Group, 1994-2014

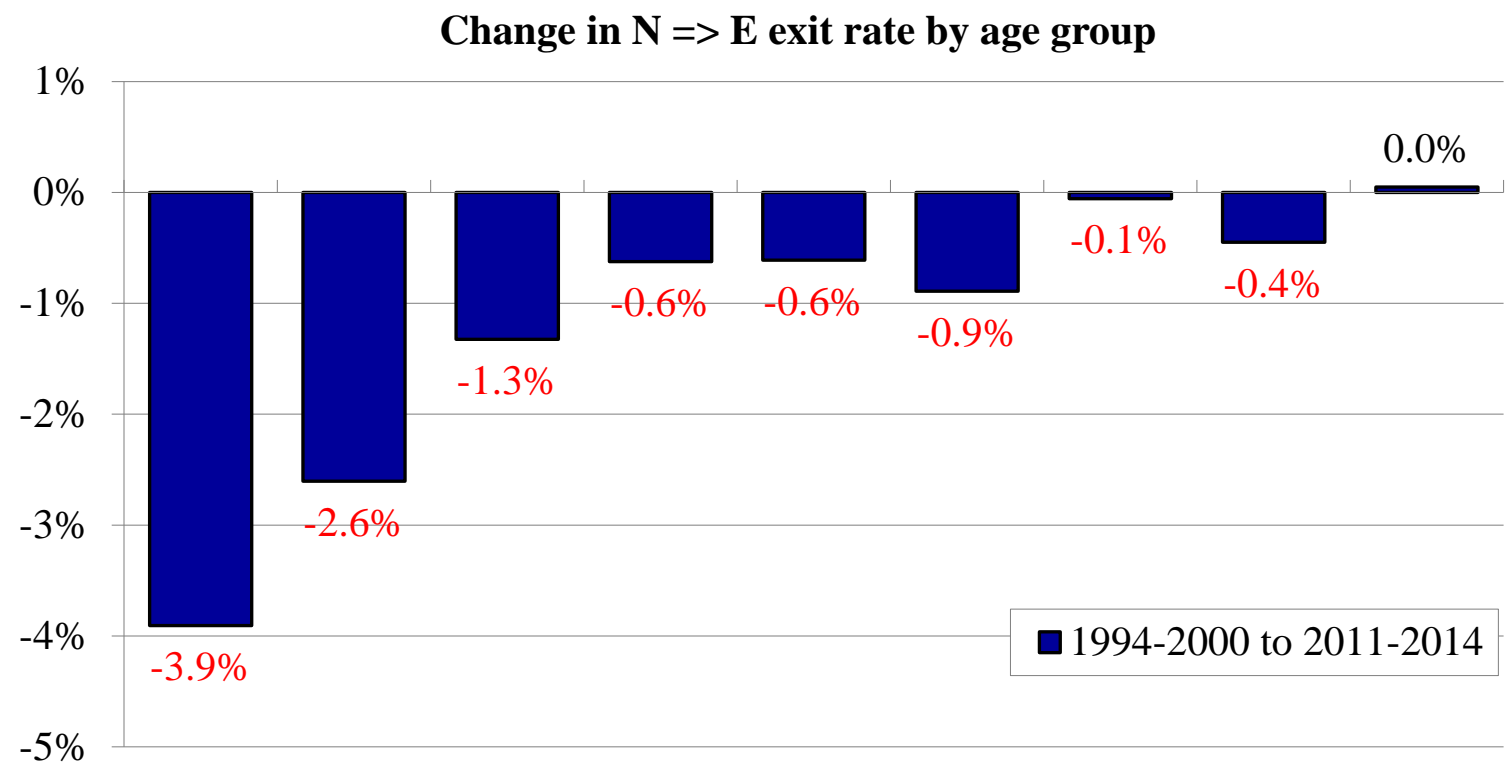

27 to 3132 to 3637 to 4142 to 4647 to 5152 to 5657 to 6162 to 6667 to 71

Change in $\mathbf{N}=>\mathbf{E}$ exit rate by age group

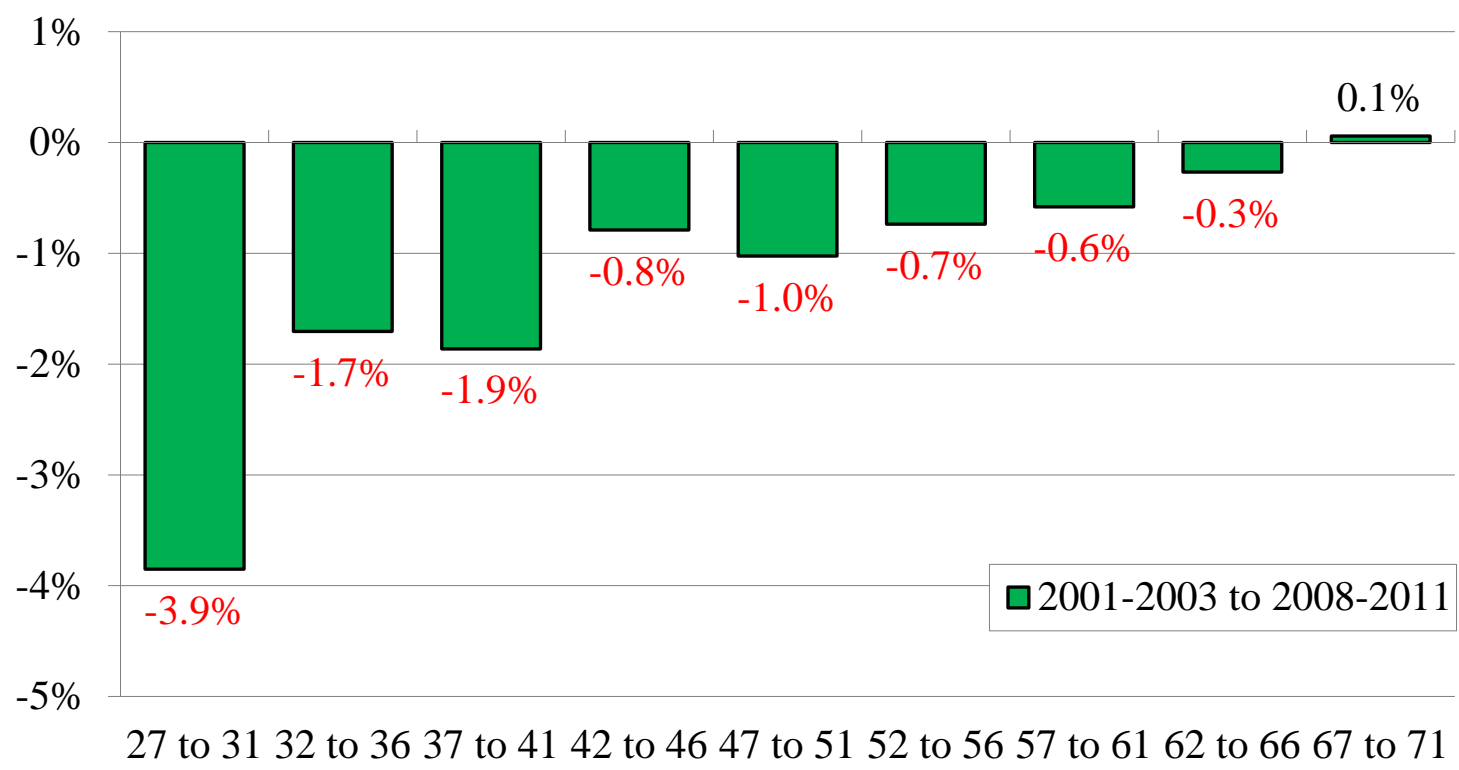

Source: Author's calculations of matched CPS interview records as described in text. Definitions of the indicated periods are given in the notes to Appendix Table 1. 
Figure 15. Monthly Transition Rates from Employment to Unemployment among Women, by Age and Educational Attainment, 1994-2000 and 2002-2007

\section{Women's $E=>\mathrm{U}$ exit rate, by schooling attainment \\ (among women age 45-54)}

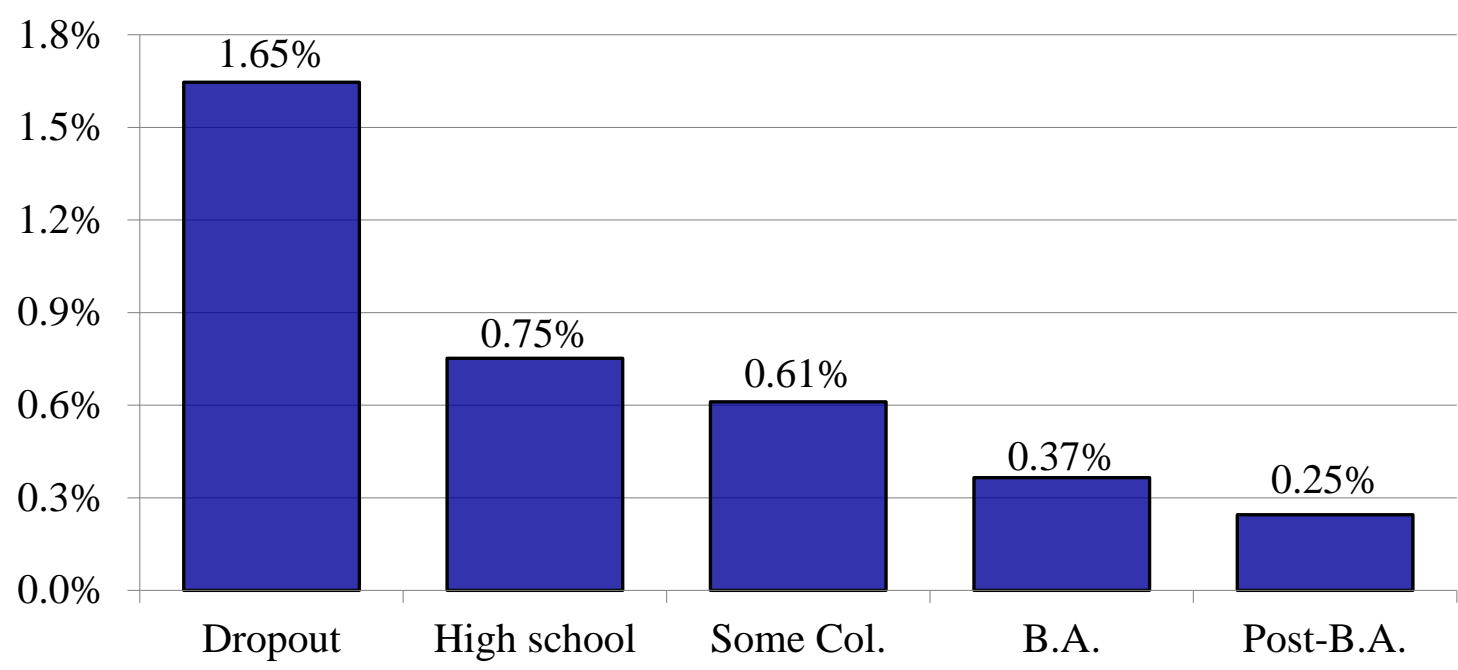

Educational attainment

Women's $E=>\mathrm{U}$ exit rate, by age

(among women with some college)

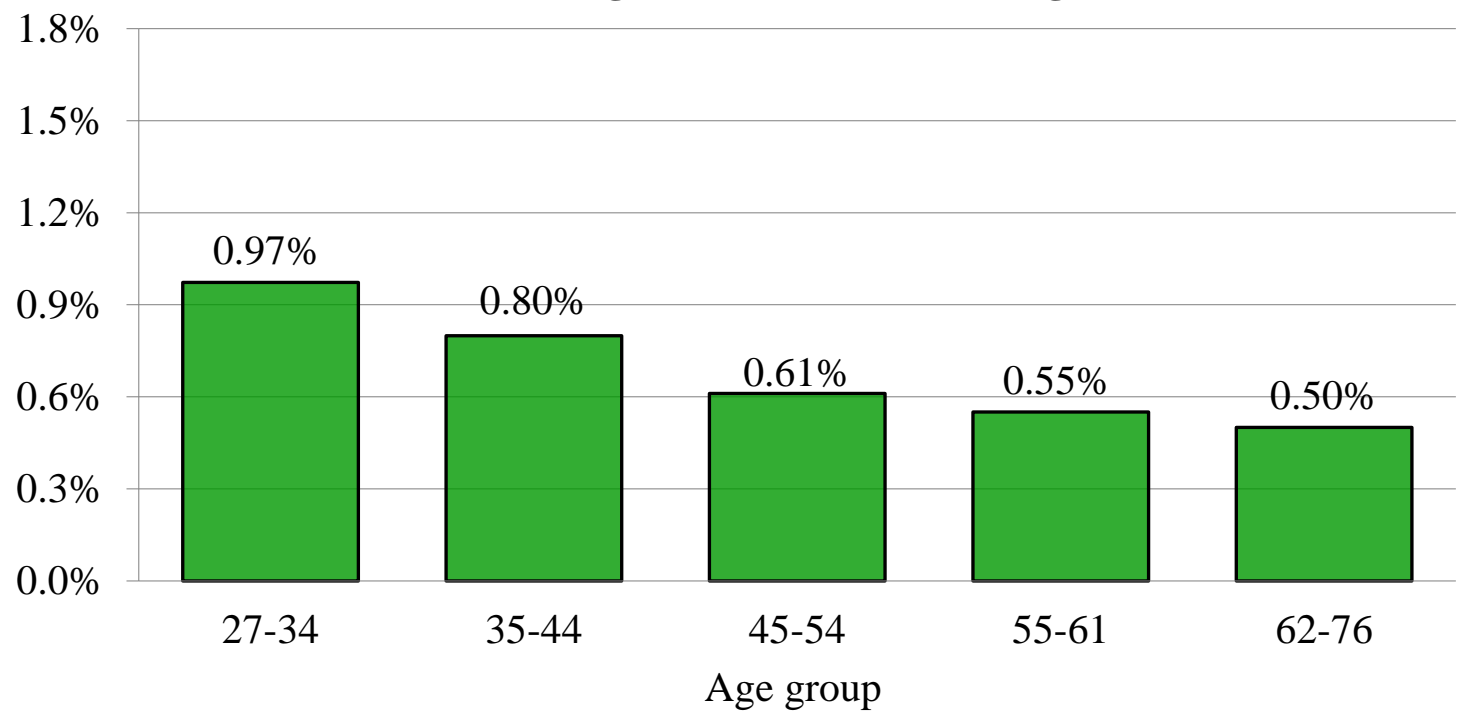

Source: Author's calculations using matched CPS interview records as described in text. Results derived from Table 1, column 1. 
Figure 16. Exit Rate from Unemployment to Employment by Duration of Unemployment Spell, 1994-2014

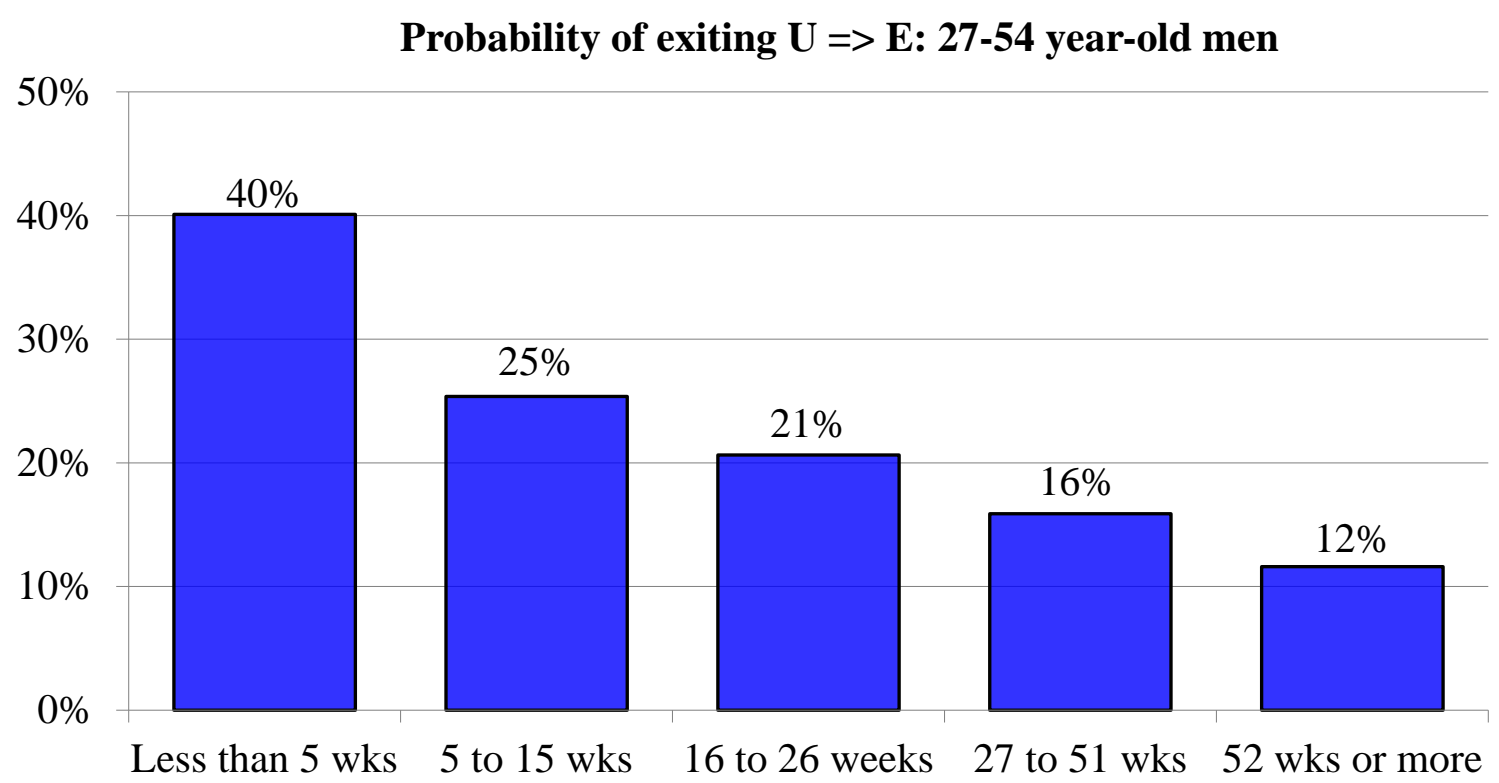

Duration of unemployment in initial month

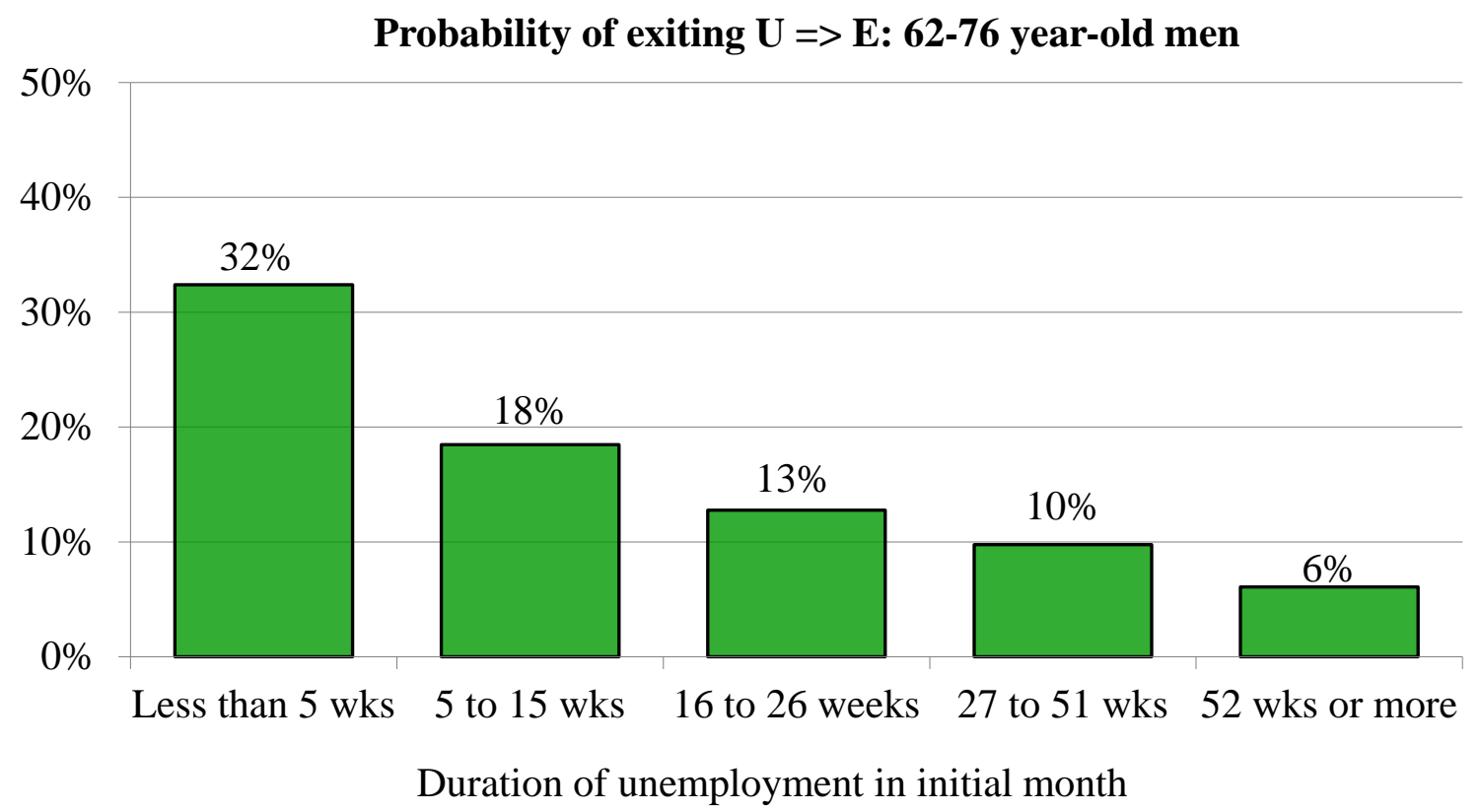

Note: Average exit rates over indicated period for men with some college education in the indicated age groups. Source: Author's calculations using matched CPS interview records as described in text. 


\section{RECENT WORKING PAPERS FROM THE CENTER FOR RETIREMENT RESEARCH AT BOSTON COLLEGE}

Elderly Poverty in the United States in the 21st Century: Exploring the Role of Assets in the Supplemental Poverty Measure

Christopher Wimer and Lucas Manfield, November 2015

The Economic Burden of Out-of-Pocket Medical Expenditures Before and After Implementation of the Medicare Prescription Drug Program Ayse Akincigil and Karen Zurlo, November 2015

The Impact of Temporary Assistance Programs on the Social Security Claiming Age Geoffrey T. Sanzenbacher, April Yanyuan Wu, and Matthew S. Rutledge, October 2015

Do Households Increase Their Savings When the Kids Leave Home?

Irena Dushi, Alicia H. Munnell, Geoffrey T. Sanzenbacher, and Anthony Webb, September 2015

Evaluating the Impact of Social Security Benefits on Health Outcomes Among the Elderly Padmaja Ayyagari, September 2015

Does Age-Related Decline in Ability Correspond with Retirement Age?

Anek Belbase, Geoffrey T. Sanzenbacher, and Christopher M. Gillis, September 2015

Job Polarization and Labor Market Outcomes for Older, Middle-Skilled Workers Matthew S. Rutledge and Qi Guan, September 2015

What Causes Workers to Retire Before They Plan?

Alicia H. Munnell, Geoffrey T. Sanzenbacher, and Matthew S. Rutledge, September 2015

Calculating Neutral Increases in Retirement Age by Socioeconomic Status

Geoffrey T. Sanzenbacher, Anthony Webb, Candace M. Cosgrove, and Natalia S. Orlova, August 2015

How Does Occupational Access for Older Workers Differ by Education?

Matthew S. Rutledge, Steven A. Sass, and Jorge D. Ramos-Mercado, August 2015

How Much Longer Do People Need to Work?

Alicia H. Munnell, Anthony Webb, and Anqi Chen, August 2015

The Challenge of Pension Reform in Georgia: Non-Contributory Pensions and Elderly Poverty

Tamila Nutsubidze and Khatuna Nutsubidze, July 2015

All working papers are available on the Center for Retirement Research website (http://crr.bc.edu) and can be requested by e-mail (crr@bc.edu) or phone (617-552-1762). 